Portland State University

PDXScholar

5-1-1969

\title{
Verbal accessibility and authoritarian family ideology: a study of 50 graduate social work students and their spouses
}

\author{
Linda Louise Metz \\ Portland State University \\ George Nathan Henderson \\ Kathleen Sue Powell \\ David Allen Wolfington
}

Sally Wong

Follow this and additional works at: https://pdxscholar.library.pdx.edu/open_access_etds Let us know how access to this document benefits you.

\section{Recommended Citation}

Metz, Linda Louise; Henderson, George Nathan; Powell, Kathleen Sue; Wolfington, David Allen; and Wong, Sally, "Verbal accessibility and authoritarian family ideology: a study of 50 graduate social work students and their spouses" (1969). Dissertations and Theses. Paper 866.

https://doi.org/10.15760/etd.866

This Thesis is brought to you for free and open access. It has been accepted for inclusion in Dissertations and Theses by an authorized administrator of PDXScholar. Please contact us if we can make this document more accessible: pdxscholar@pdx.edu. 
AN ABSTRACT OF THE GROUP THESIS OF Linda Louise Metz, George Nathan Henderson, Kathleen Sue Powell, David Allen Wolfington, and Sally Wong for the Master of Social Work presented May 23, 1969.

Title: Verbal Accessibility and Authoritarian Family Ideology in Marriage: A Study of Fifty. Social Work Graduate Students and Their Spouses.

APPROVED BY MEMBERS OF THE GROUP THESIS COMMITTEE;

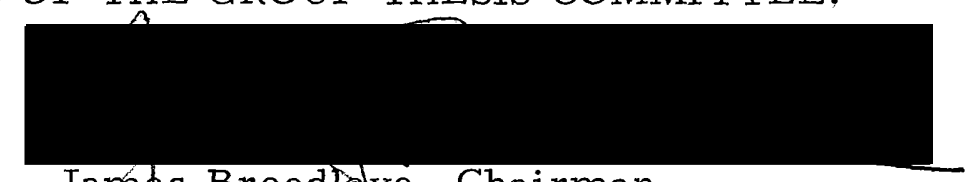
Jamies Breedlolve, Chairman
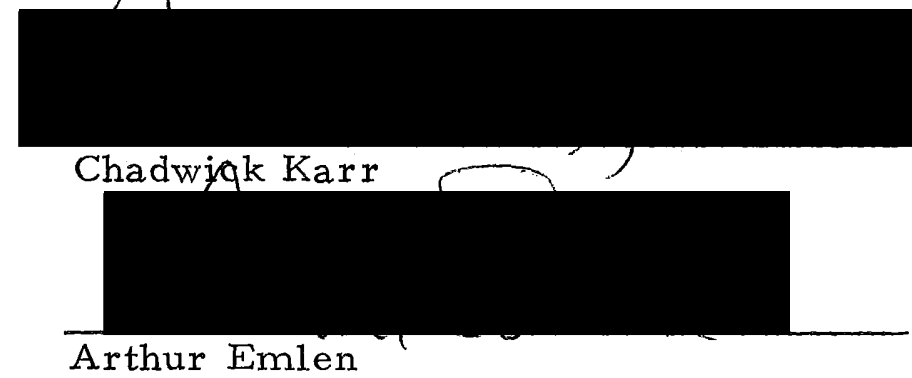

This thesis is the fourth in a series of empirical investigations concerned with symbolic interaction in marriage.- Its basic assumption is that personal predispositions of marital partners as well as the social context of their marriage influences marital intimacy particularly the partners' readiness to communicate verbally with each other about important attitudes and feelings.

Fifty married graduate students attending Portland State University School of Social Work and their spouses comprised the 
sample. The subjects responded to three instruments: (1) a personality scale (Authoritarian Family Ideology--AFI) developed by Jane Loevinger, (2) a measure of verbal accessibility (VA), and (3) a measure of social network based on the works of Elizabeth Bott. Four hypotheses were tested:

(1) the greater an individual's authoritarian family ideology (AFI), the less will be his verbal accessibility (VA).

(2) the greater a married couple's AFI, the less will be the marital VA.

(3) the greater the connectedness of the couple's social network, the less will be the marital VA.

(4) the greater the connectedness of a couple's social network, the greater will be the spouses' combined AFI.

The Pearson Product Moment Correlation was used in the data analysis. The data supported the first and second hypotheses, with moderately low correlations being found. Results obtained were statistically significant at least at the .05 level and the hypotheses of inverse relationships between AFI and VA for both individuals and couples were accepted. The data did not support the hypotheses concerned with the relationship between a couple's social network, marital VA, and marital AFI.

Generally, the study revealed that marriages in which spouses displayed less willingness for reciprocal verbal exchanges appeared 
to be more authoritarian in structure. Whereas those marriages in which spouses had a greater proclivity for mutual self-disclosure appeared less rigid and conventional. The study did not provide evidence of a relationship between the social context of marriage and ideological preferences. This raised a question regarding the validity of the instrument used to measure social network. A more precise instrument would have provided more definitive results. 


\section{VERBAL ACCESSIBILITY AND AUTHORITARIAN FAMILY IDEOLOGY: A STUDY OF 50 GRADUATE SOCIAL WORK STUDENTS AND THEIR SPOUSES by}

LINDA LOUISE METZ GEORGE NATHAN HENDERSON KATHLEEN SUE POWELL DAVID ALLEN WOLFINGTON SALLY WONG

A group the sis submitted in partial fulfillment of the requirements for the degree of MASTER OF SOCIAL WORK 1969 
TO THE OFFICE OF GRADUATE STUDIES:

The members of the Committee approve the thesis of Linda Louise Metz, et al. presented May 23, 1969 (Date)

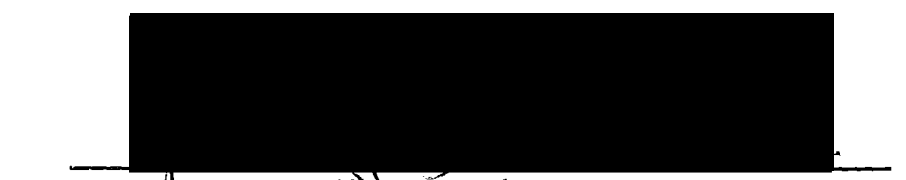

Jamfs Breedldve, Chairman

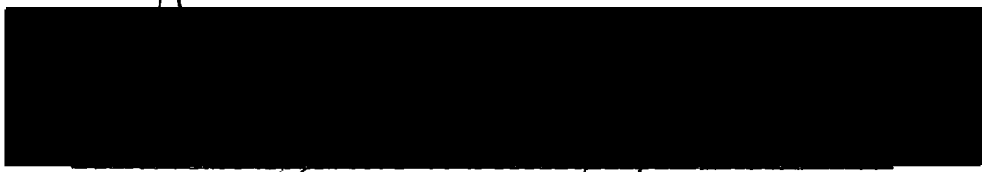

Chadwick Karr

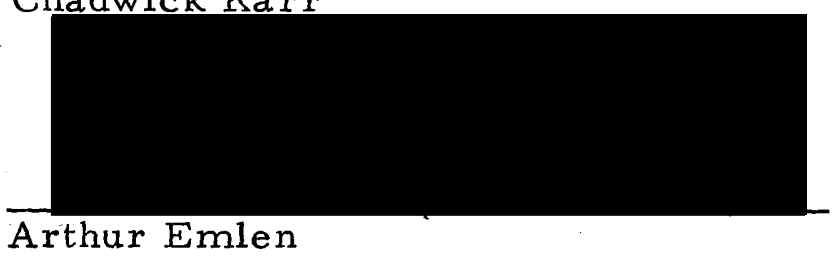

APPROVED:

Gordon Hearn, Dían, School of Social Work

Daniel E. Jennings, Acting Dean

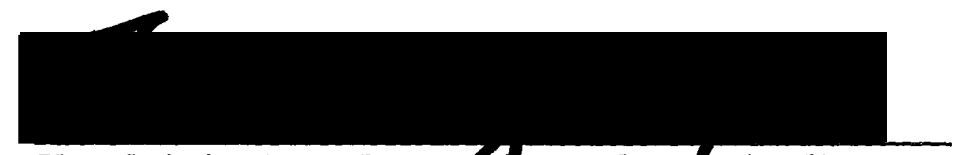

Fredrick Cox, Dean 6 Graduate Studies

June, 1969 


\section{ACKNOW LEDGEMENTS}

We would like to express our deep appreciation and indebtedness to those whose efforts and contributions made this study possible.

The Thesis Committee

Dr. Chadwick Karr, Portland State University Psychology Department; Dr. Arthur Emlen, Portland State University School of Social Work

The Advisor to the Project

Dr. James Breedlove

The Typist

Mrs. Illa W. Atwood

The Participating Students at Portland State University School of Social Work and their Families. 
TABLE OF CONTENTS

PAGE

ACKNOWLEDGMENTS ..............................

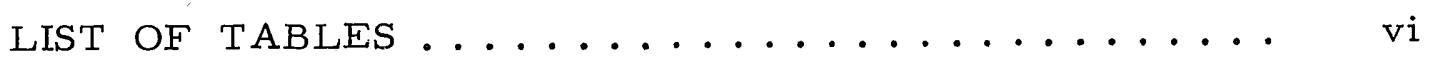

CHAPTER

I INTRODUCTION .................. 1

Marriage as Adult Socialization ....... 1

Concept of Personality ........... 2

Personality Development and Symbolic Interaction ............... 4

Personality Development in Marriage ... 7

Verbal Accessibility ........... 8

Authoritarianism in Marriage ...... 11

II THEORY AND HYPOTHESES ABOUT

VERBAL ACCESSIBILITY ......... 14

Purpose of the Study ............. 14

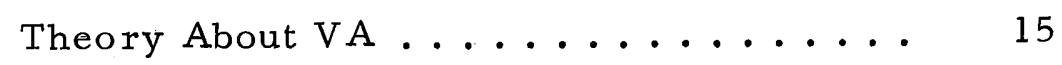

Theory About AFI .............. 19

Repression of Instinctual Tendencies . 20

Externalization of Instinctual

Tendencies ............ 20

Adherence to Conventional, Middle-

Class Values............ 21

An Exploitative Parent-Child Rela-

tionship.............. 22

An Exaggeration of Sex Roles ..... 23 
CHAPTER

Theory About Social Network ....... 25

Hypotheses ....................... 28

III METHODOLOGY .................. 34

Introduction ................... 34

Selection and Construction of Instruments . 34

The Sample.................... 37

The Pretest ...................... 38

Collection of the Data.......... 39

Description of the Sample ........ 39

Scoring the Data ............... 41

IV FINDINGS ...................... 44

Data Analysis ............... 44

Consensus of Husband's and Wife's Responses ................ 48

Relationship Between AFI and RWBR Scores................... 49

Hypothe sis Testing ............ 50

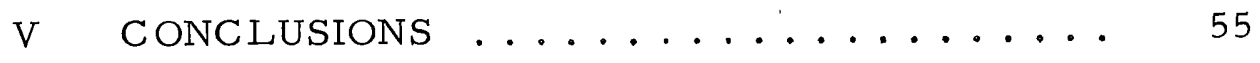

Discussion of Findings .......... 55

Theoretical Considerations ........ 64

Implications for Further Studies ...... 69

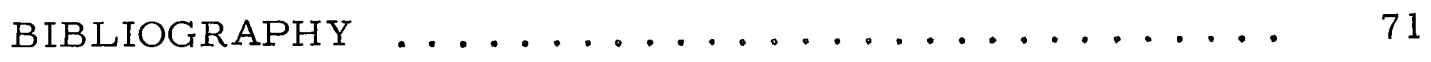

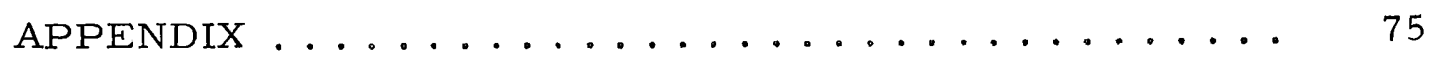




\section{LIST OF TABLES}

TABLE

PAGE

I Descriptive Characteristics of the Sample ....

II Results of Test Scores on Authoritarian Family

Ideology (AFI), Rejection of Woman's Bio-

logical Role (RWBR), Verbal Accessibility

$(\mathrm{VA})$, and Social Network (SN) .......

III AFI and VA Scale Data by Sex and Student Status .

IV $\quad t$ Tests of AFI Scale Data by Sex and Student

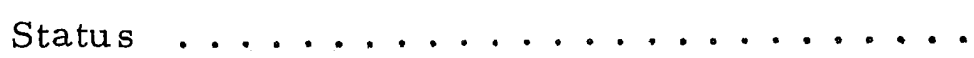

V $\quad$ t Tests of VA Scale Data by Sex and Student

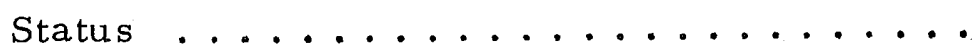

VI Correlations Between Husband's and Wife's

Responses on AFI, RWBR, and VAScales .

VII Correlations Between AFI and VA Scale Data by

Individuals and Couples ...........

VIII A Marital Typology ..............

IX Verbal Accessibility (VA) for Three Target

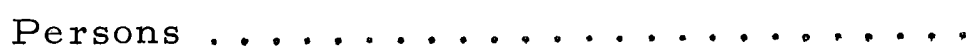




\section{CHAPTER I}

\section{INT RODUCTION}

\section{MARRIAGE AS ADULT SOCIALIZATION}

This study of the marriages of 50 graduate social work students and their spouses utilizes the interactional approach to marriage. Marriage is seen as a continuum of the on-going socialization process beginning at birth and ending with death. The marital state is one in which most people spend the greater portion of their lives. Because of the intimacy of the marital relationship, the influence of each spouse upon the other is profound. It is seemingly important that marital interaction is of such a quality as to promote adult socialization and personality development. There are successful marriages in which each spouse seems to gain in personality integration and complexity, while other marriages may become destructive to the point of complete physical and mental breakdown for one or both spouses.

We as sume that one crucial determinant for success in marriage is that of verbal accessibility. This is defined by Polansky (1965) as the degree of readiness of a person to communicate verbally, and to permit others to communicate with him about his most important or determinant attitudes. Determinant attitudes are defined as those 
for which change is most likely to bring about changes in other related or "dependent" attitudes.

In addition, we assume that variations in personality characteristic as well as the social context of married couples would have greater significance for marital interaction, and therefore on the life styles of these marriages. This project evaluated a series of correlations involving the following variables: verbal accessibility (Polansky, 1965); authoritarian family ideology, a specific personality dimension (Loevinger, 1962); and social network (Bott; 1959). According to Polansky (1965), verbal accessibility or (VA) is dependent on two variables: 1) the enduring characteristics of the individual, and 2) the release of inhibiting factors in a given situation--"VA might be regarded both as a variable reflecting forces at work in the social situation and as a meaningful attribute of personality of character" (p. 13). Authoritarian family ideology is descriptive of the degree of flexibility with which a person approaches family norms. Social network refers to the collectivity of social relationships which a couple maintains with persons outside the nuclear family.

\section{CONCEPT OF PERSONALITY}

Since personality is an important variable affecting marital interaction, it is pertinent to discuss it as a concept. Stryker (1959) 
defines it as "the organization of persistent behavior patterns" (p. 112). Gordon Allport (1960) has stated that personality is what a man really is, external actions merely providing clues to the reality within the individual. But then the question arises as to man's essence. Does individual uniqueness result from one's makeup, or is it a product of the environment? Currently, the dichotomy of "heredity or environment" is essentially meaningless. Teicher (1959) denotes that "Society does not exist apart from man and man cannot be human without society" (p. 442). The following comprehensive definition is by Kluckhohn and Murray (1953).

The personality of an individual is the product of inherited dispositions and environmental experiences. These experiences occur within the field of his physical, biological and social environment, all of which are modified by the culture of his group. Similarities of life experiences and heredity will tend to produce similar personality characteristics in different societies (pp. 66-67).

An important aspect of personality is that from its very inception, it remains in a state of flux. Man is seen as an actor, as well as a reactor. One never becomes, but is in a state of becoming. While personality is not without stability and changes in determinant attitudes are difficult to achieve, it is the capacity for change that provides the basis for psychotherapy and social work. 
III. PERSONALITY DEVELOPMENT AND SYMBOLIC INTERACTION

We assume that personality "unfolds" through a series of progressive steps. One is not born with a particular personality but with certain inherent predispositions capable of developing in different directions. An infant is neither social nor antisocial, but rather an asocial being with the potentialities for social development. He is an active organism with "impulses, "but the se are not channelized or directed toward any specific ends (Stryker, 1959).

Erikson (1959) states:

Personality can be said to develop according to steps predetermined in the human organism's readiness to be driven toward, to be aware of, and to interact with, a widening social radius, beginning with the dim image of a mother and ending with mankind, or at any rate that segment of mankind which "counts" in the particular individual's life (p. 52).

Erikson's statement stems from Freud's concept of the epigenetic principle which maintains that proper developmental progress requires the mastering of phase-specific tasks in a sequential manner. This principle grew out of embryology, in which the proper unfolding of the embryo depends upon each organ's arising out of its anlage in the proper sequence and at the proper time ( Lidz, 1968). Fortunately, personality development is not so rigidly set as embryonic maturation and even though development is impeded or altered, compensations are possible, and deficiencies can be turned into strengths. 
Personality develops through a series of social acts.. According to Stryker (1959), the understanding of symbolic interaction begins with the social act. First he defines the "act" as behavior which stems from an impulse and requires some adjustment to appropriate objects in the external world. A "social" act is described as one in which the appropriate object is another individual. When two persons in a recip rocal relationship respond to cues emanating from each other in a manner which is recognized as significant by each, they engage themselves in the process of communication.

Sullivan (1946) refers to the communication between an infant and his mother as "emotional contagion or communion." These are feelings. transmitted by the pressure of touch, the tonal quality of voice and bodily tension. It is through these daily verbal and non-verbal interactions that an infant first begins to experience feelings of "self." Later, when he responds to his own words as others respond to them and modifies his behavior in anticipation of the response others will make, his words are "significant symbols," and human intercommunication is then achieved (Hill, 1965).

When the interactional process proceeds normally: between a person and those who are important to him, the growing ego organizes into consistent patterns of behavior and becomes well differentiated. The self emerges and can take the role of the other, thereby having the capacity to see the world objectively as well as subjectively, 
and to realize the difference. The healthy ego accepts the changes, privations, and frustrations inherent in the life process and uses them as stimuli for further growth. Emotionally, the healthy personality is relatively free from infantile erotic ties and is able to enter into a close relationship like marriage on a give-and-take basis (Hill, 1965). Because the ego has achieved organizational unity, it can differentiate between disparate drives and channel the se impulses in socially acceptable ways.

Inter ruption or disruption of this vital developmental process, especially during the formative years, may be so disastrous as to result in death or at the very least some damage to the developing personality. Studies by Bowlby (1966), Spitz (1945), and Goldfarb (1955), have shown that babies lacking a consistent, positive interactional experience with a significant person, do not develop normally either physically or emotionally. These studies on maternal deprivation concluded that prolonged deprivation of the young child of maternal care may have grave and far-reaching effects on his character which may last a lifetime. Furthermore, the ability most affected was speech, the ability to express being more retarded than the ability to understand (Bowlby, 1966).

Bowlby states:

Maternal deprivation has a differential effect on different processes, especially language and abstraction, and certain aspects of personality, most especially the ability to 
establish and maintain deep and meaningful interpersonal relations, but also the ability to control impulse in the interest of long range goals (p. 341).

\section{PERSONALITY DEVELOPMENT IN MARRIAGE}

People getting married come into the marital state with fairly stabilized personalities. There is consistency to their patterns of behavior. But marriage, as a part of the life process for most people, entails a number of ever-changing developmental tasks. These tasks are intra-personal, interpersonal, and social in nature. Duvall (1957) listed a number of family developmental tasks that span the family life cycle. They are to establish and maintain:

1. An independent home

2. Satisfactory ways of getting and spending money

3. Mutually acceptable patterns in the division of labor

4. Continuity for mutally satisfying sex relationships

5. Open system of intellectual and emotional communication

6. Competency in bearing and rearing children

7. A workable philosophy of life (p. 336).

The successful accomplishment of these developmental tasks would demand a great amount of adjustment, flexibility, and readjustment on the part of both spouses and subsequently other members of the family. A person who is rigid and inflexible can conceivably hamper marital adjustment and personality development, for it is in the free give-and-take of a significant relationship that personality grows.

It seems that marriages would be more likely to succeed when 
the spouses have flexible and adaptive personalities. However, the real essence of a marriage is in its interaction. The marital relationship represents more than the sum of its personalities, although it still bears:identification of its component parts.

The relationship depends not so much on the stability of the separate personalities, but what emerges as a result of their interaction. Marriage as an on-going adult-socialization process is possible for those beset with personality problems as well as for those who are not. It is Ackerman's (1954) contention that the outcome in mental health terms of a particular marital relationship is not contingent exclusively on the character of the neurosis of the individual partners, but on the dynamic part that neurotic conflict plays in the complex process of the integration of each partner's personality into their reciprocal roles of husband and wife. Lidz (1968) contends that while personality problems may be helped by marriage, they more commonly create difficulties.

\section{VERBAL ACCESSIBILITY}

Verbal accessibility, the degree of readiness of one person to communicate to anothe $r$ about his determinant attitudes, is related to personality: an important variable affecting marital interaction.

"VA is an aspect of ego-functioning, interlocking with and dependent 
upon organizational unity and the capacity for self-observation" (Polansky, 1965, p. 18).

When personality development has proceeded normally, when the person has been able to achieve a firm sense of self as an independent object, it would seem that VA would be high. High VA in marriage can facilitate marital adjustment to the degree that each spouse is willing to reveal to the other his feelings, beliefs, attitudes, wants, and role expectations; however, high VA does not of itself guarantee marital adjustment.

As Jourard states:

You cannot love another person, that is, behave toward him so as to foster his happiness and growth, unless you know what he needs. And you cannot know what he needs unless he tells you (Jourard, 1964, p. 3).

It is Jourard's opinion that a person who does not disclose himself fully and truthfully to at least one significant person is selfalienated. A self-alienated person can never love another person, nor can he be loved by the other person since he neither knows himself nor the other person. It seems that effective loving calls for knowledge of the object (Jourard, 1964). VA in marriage may therefore be a critical factor in enhancing the growth of love between the spouses.

VA as a stable but not rigidly fixed feature of personality, varies with time, social situation, and target persons. Currently 
the psychological well-being and emotional fulfillment of hu sband and wife have become primary criteria upon which a successful relationship is established. The trend is toward a companionship type marriage which emphasizes the equality of the spouses. It expects them to get emotional and intellectual stimulation from each other, to develop their individual personalities in a whole some manner, and above all to find happiness in each other's company (E. W. Burgess, P. Wallin, and G. D. Shultz, 1954). Couples adhering to a companionship type marriage would seem to be motivated toward a higher $\mathrm{VA}$ in their marriages.

A couple's social network, that is the number and connectedness of its social relationships, may be related to VA between marital partners. Connectedness refers to the extent that all or some of the couple's friends and relatives maintain social contacts with one another irrespective of the couple's presence. High connectedness, or a close-knit network (Bott, 1959) with many inter-relationships, may be associated with lower emotional involvement in the marital relationship. A low connectedness, or a loose-knit network (Bott, 1959) with few or no inter-relationships, may be associated with higher personal satisfactions in marriage and, possibly, greater VA between the spouses.

Regarding target persons, Jourard (1964) points out that married subjects, male and female, disclose less to their parents and 
friends, and more to each other. The study by Kresse, et al. (1967), is in accordance with Jourard's finding showing a high percentage of positive responses toward the spouse as a target person over other target persons.

During the process of socialization, a person tends to see the world as it has been interpreted to him. Reality is never experienced as it really is, but is altered in the service of our emotions, beliefs, and values. Walker, et al. (1968), suggests that the concept of another is as important a variable in determining the quality of relationship as is the concept of verbal accessibility.

It has been shown . . . that when persons receive contradictory information about another they often misperceive entire sets of facts in order to develop an internally consistent view of that person ... (and)... provide themselves with a picture of the other which remains relatively stable and consistent" (Levinger and Senn, p. 10).

In a good relationship, certain illusions possess a positive function and value like protecting mutual self-esteem. The healthy, personality is effectively discriminatory in his use of VA in terms of roles and relationship in marriage.

\section{AUTHORITARIANISM IN MARRIAGE}

Authoritarianism as one outcome of the socialization process is descriptive of a personality characterized by varying aspects of rigidity. According to Adorno, et al. (1950), the most essential 
feature of this personality structure is lack of organization. The ego is not only constricted but quite undifferentiated. Ego growth achieved through the free give-and-take of spontaneous interaction between a child and the significant persons in his world is withheld in a hie rarchical, authoritarian parent-child relationship.

This exploitative parent-child relationship is likely to carry ove $r$ into a power-oriented, exploitatively dependent attitude towards one's spouse. The authoritarian spouse re-lives in the marital situation, the situation which had existed in his childhood. He has neither achieved independence from his parents nor has he resolved infantile erotic ties. Because he is afraid of what he might reveal if he talks about his feelings, the authoritarian person prefers to keep every inte rpersonal relationship, even the marital one, highly structured and perfunctory. He may be unhappy and may even know that his spouse is unhappy, but he is fatalistic about life and believes that he cannot change his fate.

Most importantly the authoritarian personality, being extraceptive, is out of touch with his real self. Therefore there is less chance for effective communication of determinant attitudes, and more chance for misunderstandings in interpersonal relationships such as the marital one.

The foregoing material in this chapter suggests that personality development is dependent on an individual's inherent predispositions 
and on symbolic interaction which may be both verbal and non-verbal. Marriage is seen as an on-going process of adult socialization effected through symbolic interaction. Verbal accessibility as one aspect of symbolic interaction is dependent on two variables--personality and the social situation. The inter-relationship of these variables within a given marriage, therefore, determines the type and quality of the marriage. 


\section{CHAPTER II}

\section{THEORY AND HYPOTHESES ABOUT VERBAL ACCESSIBILITY}

\section{PURPOSE OF THE STUDY}

This study is a continuation of a series of investigations concerned with verbal aspects of marital interaction. Its main assumption is that personal predispositions of marital partners as well as the social context of their marriage influence marital intimacy, particularly the partners' readiness to communicate verbally with each other about important attitudes and feelings.

The study has four objectives. The first is to study the relationship between the verbal accessibility (VA) of the individual among urban middle-class spouses and the extent of authoritarianism in their family ideology (AFI). The second objective is to develop a scale for measuring the connectedness of the se couple's social network. The third is to study the relationship between marital VA and the couple's social network. Marital VA is used here to describe the degree to which spouses are verbally accessible to one another. And the final objective is the investigation of the relationship between AFI and the couple's social network. 


\section{THEORY ABOUT VA}

Polansky (1965) defines verbal accessibility (VA) as "the degree of readiness of the person to communicate verbally, and to participate in communication about, his determinant attitudes" (p. 6). This readiness he describes as the resultant of a force field which exists at a particular point in the individual's life space. The phrase "determinant attitudes".is used to refer to those attitudes whose change seems most likely to bring about changes in other related attitudes thus resulting in alterations in the individual's personality structure.

VA, as an aspect of ego functioning, is characterized as a stable, though not rigidly fixed feature of personality which indicates over-all "organizational unity" of the personality and the individual's related capacity for self observation. That the individual himself chooses those with whom he wishes to communicate suggests that VA fluctuates in response to one's immediate environment. RickersOvsiankina and Kusman (1958) therefore contend that VA can be considered as a "quasi-stationary" state which varies with external as well as internal conditions.

Verbal expression of important feelings serves several positive functions. First, it provides a basis for the cognitive structuring of one's position in relation to the social environment by furnishing a 
source of information. which facilitates his understanding and explanation of, control over, and prediction about events which affect him.

Second, verbal expression offers a channel for the release of emotional tensions and, at the same time, may serve to ward off the deleterious effects of defense mechanisms such as withdrawal, projection, and denial. Rapaport (1951) contend s that communication not only enriches the store of experiences, thereby counteracting ego-limitations, but also enhances the "synthetic function of the ego" (p. 727f). Mere communication, however, does not necessarily give an accurate description of one's verbal accessibility. Polansky (1965) purports that the verbose individual may utilize his conversational skills to evade rather than reveal important aspects about himself. By doing so communication of attitudes is relegated to an impersonal level which may affect an individual's failure to establish a sense of independence and singular identity. Polansky (1965) concludes that "the extent to which a person is accessible to interpersonal communication is a result of a subtle balance between the contractive need to protect vulnerable areas of the personality and an expansive tendency toward social, cognitive, and emotional selfexpression" (p. 32).

Jourard (1959a) deals with a behavioral aspect of verbal expression and refers to it as self-disclosure. Self-disclosure is defined as the process of revealing one's thoughts, feelings, and needs: to 
another individual through direct verbal expression. By necessity, this process requires that the individual engage himself in an active endeavor toward "real-self-being" or knowing oneself. This discovery of the breadth and depth of one's needs and feelings and the nature of self-affirmed values is enhanced and sustained by disclosing oneself to others; the total effect being not only a potential means of achieving a healthy personality but also the ultimate stabilization of a healthy personality.

Jourard (1959a) goes on to say that the inability to know one's "real self" and disclose it to others is related to neurosis, and that an individual thus self-alienated can never truly love nor be loved by another person.

In one study dealing with the self-disclosure behavior of men, Jourard and Landsmar (1960) state that "people who wish to become known and understood must disclose themselves" (p. 183). The study revealed that the correlation between one's self-disclosure and knowing another individual was stronger than that between one's selfdisclosure and liking that individual, and that although object cathexis was a greater factor in disclosure rates among women, both men and women showed a marked "dyadic effect" in their disclosure patterns. "Dyadic effect" is used here to mean the reciprocal exchange of communication where the individual receives disclosure from others in proportion to the amount he discloses to them (Jourard, 1961). 
These findings have particular relevance to intimate, interpersonal relations such as those between the spouses and are supportive of Nooney and Polansky's (1962) contention that intimate conversation among individuals serves to "promote a sense of mutual incorporation (i.e. 'As you really know me, I become part of you. ')" (p. 34). They further state that the readiness for intimate or free conversation "reflects an increase in (driving) forces toward selfrevelation" and a "lowering of restraining forces against verbalizing deeper feelings" (p. 34). This suggests that the intimate interpersonal relationship between husband and wife would be highly conducive to an elevated degree of VA between the marriage partners.

Jourard (1961) goes so far as to state that "the relationship between a person and his spouse is 'closer', insofar as self-revelation is concerned, than any other everyday relationship a person has entered up to that time" (p. 192). He contends that seemingly an individual's fullest self-disclosure usually manifests itself in a person of the opposite sex which would then imply that persons unable to achieve a close relationship with an opposite-sex partner would remain with much "self" that is not expressed or achieved. If the conditions of a marriage were such that a significant point of mutual self-disclosure was not reached between the spouses, it could be surmised then that the spouses' personal growth would be arrested and 
the interpersonal growth and enrichment of the marital relationship would not reach its fullest capacity.

\section{THEORY ABOUT AFI}

Adorno, et al. (1950) uses the term personality to mean an essentially enduring organization of forces or predispositions within the individual. These forces are not in themselves responses; that is, they are not synonymous with behavior nor are they necessarily manifest in overt specific behavior patterns. Instead, they lie "behind behavior and within the individual" and this can be described as "readinesses for response" or determinants of behavior (p. 5). Such readinesses or proclivity toward overt expression suggests that personality is in a continuous state of flux as the individual acts and reacts to the environment.

The forces of personality are primarily personal needs (drives, wishes, emotional impulses), and their verbal expression takes the form of opinions, attitudes, and values. Since the term ideology commonly refers to the individual's way of looking at man and society, personality may be regarded as a determinant of ideological preferences (Adorno, et al., 1950). It follows then that the application of one's manner of viewing his environment as dictated by personal needs will be related to specific behavior patterns.

Although the elastic quality of personality facilitates the 
individual's adaptation to his environment, it is its basic structure which provides a guideline for consistent patterns of behavior in widely varying situations. This personality structure within the individual is capable of initiating action upon the environment through a process of selecting appropriate learned behavior in response to external stimuli. Although always modifiable, personality, and its subsequent overt manifestations, are frequently very resistant to change.

Generally speaking, the Authoritarian Family. Ideology (AFI) has been described by Adorno, et al. (1950), Loevinger (1962), and Levinson and Huffman (1955) as one characterized by:

Repression of Instinctual Tendencies

Typically, the authoritarian personality is predisposed to many fears, weaknesses, passivity, sex impulses, and aggressive feelings toward authoritative figures, particularly his parents. These tendencies are difficult for the individual to openly accept as part of his own ego and, as a result, he fails to integrate them satisfactorily with his conscious self image (Adorno, et al., 1950).

\section{Exte rnalization of Instinctual Tendencies}

To deal with these dispositions the authoritarian personality makes massive use of ego defenses such as projection, denial, and reaction-formation to the extent that much of what cannot be accepted 
as part of one's own ego is ascribed to the external world. These defenses aid the individual in his social encounters by allowing him to rationalize his instinctual tendencies as normal responses to a hostile and threatening environment over which he has no control. Related to both repression and externalization of instinctual tendencies is the tendency toward avoidance of introspection. An individual expending large amounts of energy to repress these tendencies has little left for either coming to know himself or disclosing himself to others. There occurs then an unconscious inability to conceptualize one's inner life which Adorno, et al. (1950) refers to as "anti-introception" and which is reflected in a lack of perception and empathy for others' thoughts and feelings.

\section{Adherence to Conventional, Middle-Class Values}

Because of his poorly integrated ego and a subsequent ineptness to establish and effect impulse controls, the authoritarian personality relies upon the external support and approval of others as a basic means of structuring his life style. Adherence to a rigid externalized set of conventional values resolves to some extent the anxiety felt over his inability to consciously admit personal weaknesses and, at the same time, his intensely felt need to protect these weaknesses from exposure to others. This over-dependency on external controls rather than inner moral responsibility manifests 
itself socially in the formation of stereotypes and strong ingroupoutgroup cleavages. Social achievement and status levels provide a basis for evaluating one's associates and little tolerance is held for persons whose values differ from those of one's chosen group. Their approach to interpersonal relationships with others is relatively restricted and superficial. Adorno, et al. (1950) contends that this approach is "counter-cathetic" in that it is effected at the expense of self-expression and emotional release.

\section{An Exploitative Parent-Child Relationship}

Relationships among authoritarian persons tend to be in clearly defined roles of dominance and submission. There is less spontaneity and affection and the unconditional parental love found in more equalitarian families is replaced by a love and acceptance based on compliance to rules and minimal disagreement. Emphasis is placed on discipline as a means of ensuring family unity.

Loevinger (1962) describes the authoritarian woman as having a punitive and controlling attitude toward many areas of child rearing and hierarchical and sentimental view of family life as a whole. She further states that this orientation is attributable to the woman's fear of her own impulses which she sees reflected in the child. Protected by her lack of perceptiveness for the child's needs, the mother's immediate response is to establish controls which regulate 
the child's behavior thus depriving him of opportunities for ego development and self control. This merely exemplifies one way in which the authoritarian personality is encouraged and maintained through the socialization process.

An Exaggeration of Sex Roles

The need to repress felt weaknesses results in a self-conception which exaggerates both ideal and characteristic features of masculine and feminine roles. The authoritarian personality sees himself only in terms of those features assigned specifically to his sex. All other traits are held in contempt and those displaying such characteristic s are considered inferior and weak. This is partly a carry-over from the exploitative parent-child relationship experienced earlier in life and is consistent with the general tendency of the se individuals to 'display 'negative identification' with the weak along with their positive though superficial identification with the strong" (Adorno, et al.', 1950, p. 387). Typically there is a separation of sex and affect particularly for men where intimate relationships with the opposite sex are depersonalized. This supports the individual's need to know and assume a specific role as defined in a dominance-submission exchange but it also encourages an ambivalence which combines an underlying disrespect for and resentment against the opposite sex with an externalized and excessive pseudo-admiration for that person 
(Adorno, et al. , 1950).

Authoritarian Family Ideology is a reflection of the authoritarian personalities of family members, particularly the parents and eventually the children as they are affected by the socialization process.

Both Loevinger's (1962) study and the Berkeley study conducted by Adorno, et al. (1950) became involved in measuring the capacity of the individual to conceptualize his "inner life." This trait which describes the extent of one's ego strengths is revealed in the authoritarian personality as a tendency toward self-conception in terms of social stereotypes. Loevinger, whose study deals exclusively with women, found this trait, as measured by the AFI Cluster, to be very similar to that measured by the Berkeley $F$ scale, which concerns itself mainly with men.

Both studies provide support for the notion that authoritarianism is a stage in the normal developmental sequence. Authoritarianism results from poor impulse control as influenced by early problems associated with ego development and leading to later problems associated with achieving a sense of identity. This is consistent with psychoanalytic theory of psychosocial development (Erikson, 1963).

However, their conclusions differ as to the position of this trait along a continuum which ranges from the "authoritarian- 
stereotyped-conventional-rigid individual to the democratic-permissive-flexible-differentiated person" (Loevinger, 1962, p. 115). Adorno's, et al. (1950) study is based on patterns abstracted from data collected on large groups of people rather than individual cases, and the results of the study are limited to trends found in individuals at the extremes of the continuum as those with middle scores were not included.

In contrast, Loevinger (1962) makes the assumption that "authoritarianism, rather than being the extreme of a trait is in fact the mid-point of a developmental sequence" (p. 116), and that the authoritarian personality can be considered an immature version of the liberal person. This is an observation not made in the Berkeley study.

\section{THEORY ABOUT SOCIAL NETWORK}

Traditionally, the family was seen as a self-sustaining social unit contained in an organized kinship group whose functions encompassed the economic, political, religious, and social aspects of the family and provided the necessary controls to regulate its life-style. Bott (1959) describes an organized group as one in which "the component individuals make up a larger social whole with common aims, interdependent roles, and a distinctive sub-culture" (p. 58).

With the development of industrialism and urbanization, the 
concept of the family unit changed from that of an extended system to one confined to the nuclear group of parents and their children. The extent of the family's functions were reduced and those once enjoyed by the extended family system were redistributed among non-family agencies in the society at large. In view of this transition, Parsons and Bales (1955) see the family as having become, on the "macroscopic" level, almost completely functionless. They claim that the family does not itself

-. engage in much economic production; it is not a significant unit in the political power system; it is not a major direct agency of integration of the larger society. Its individual members participate in all the se functions but they do so 'as individuals' not in their roles as family members (p. 16).

In effect, the social control over the family was reduced so that no single agency has complete, continuous governing power over it. This allows the family, within broad limits, to make its own decisions and regulate its own affairs which Parsons and Bales (1955) define as those involving the socialization of the child and the stabilization of the adult personality.

At the same time, however, the urban nuclear family has become an isolated, "individuated," relatively autonomous social unit. Displaced from an extended kinship system, the family now finds itself placed in a "structurally unsupported" situation where emotional ties and bonds of mutual assistance are substantially 
reduced and the vulnerability to collapse under stress is increased. In an effort to correct this situation, family members may turn to one another for emotional support and as sistance or seek similar support in a network of social relationships outside the immediate family. This is not to suggest, however, that the one course of action is selected to the exclusion of the other.

Bott (1959) states that:

Conceptually, the network stands between the family and the total social environment. The variability in the total environment permits choice in the field of external social relationships; choice is affected both by situational factors and by the personalities of the members of the family (p. 98).

Social network is here defined as a social configuration in which some, but not all, of the component external units maintain relationships with one another. The number of relationships which the se external units (relatives, friends, acquaintances, etc.) share independently of the family is a measure of the degree of "connectedness" of the social network peculiar to each family and relative to the networks of other families.

Bott (1959) distinguishes between two types of networks and refers to them as loose-knit and close-knit. The term loose-knit describes a network in which there are few relationships among the component units. This type is most likely to develop where the external relationships are relatively discontinuous in space and time 
and is characteristic of families whose residence frequently changes. In contrast, close-knit describes a network in which there are many relationships among the component units. This type occurs more often when the marital couple, together with friends, relatives, etc., have grown up in the same local area and continue to live the re after marriage.

Factors such as economic ties, type of neighborhood, opportunities for making relationships outside the existing network, and social mobility affect the degree of connectedness peculiar to each network. These variables, in combination with the family's personal needs, create a complex of forces which also affect the extent of the network or the actual number of external units with whom the family chooses to form relationships.

\section{HYPOTHESES}

Based on the material presented, . it would appear that a person who conceptualized his environment as being hostile and threatening would be reluctant to expose himself to others for fear of personal assault. Since one's livelihood usually demands social encounters, such an individual would be required to select from a vast repertoire of values those which are most conventionally espoused. This would not only serve as a camouflage for personal fears and weaknesses but also serve as the least stress-provoking means of dealing 
with others.

In his quest for conformity to society at large and a desire to simultaneously protect himself from exposure, such an individual sacrifices much in terms of self-assertion and making himself known to others as a unique person. This suggests that the relationships formed with others are maintained at a superficial level in which personally important thoughts, feelings, and needs are left unexpressed and unrealized.

Based on these observations, we contend that the degree of readiness to communicate verbally about determinant attitudes would be more restricted for the individual holding to conventional, or authoritarian, ideological preferences than for the individual entertaining a less rigid, externalized value system.

We, therefore, hypothesize that:

Hypothesis I. The greater an individual's authoritarian family ideology (AFI), the less will be his verbal accessibility (VA).

It can be assumed that persons holding to an authoritarian ideology will engage themselves in intimate relationships despite inhibitions for verbal expression of determinant attitudes and that some of these relationships will culminate in marriage.

Nonetheless, the personality organization of the individual would continue to reflect poor impulse control and an inadequately 
defined identity. Chances are that, in this case, the selection of a spouse would be based on the perception of similar personality traits. This would provide a relationship supportive of an ego unable to withstand exposure and demanding of a situation which does not provoke self-revelation. Husband-wife interaction would be dictated by rigid, predetermined ideas based on a dominance-submission exchange consistent with the authoritarian person's conception of masculine and feminine roles and dedicated to the goal of instrumental, rather than expressive, task achievement. Adorno, et al. (1950) contends that this need to set off clear demarcation lines and to ascertain superiorities and inferiorities inhibits the libidinization of object cathexis in interpersonal relationships and thus reduces the degree to which individuals know one another.

It would appear then that the predisposition of the spouses to underplay self-revelation in combination with the externalized roles they fill would inhibit the degree of readiness with which the couple communicates determinant attitudes to each other (marital VA).

We, therefore, hypothesize that:

Hypothesis II. The greater a couple's AFI, the less will be the marital VA.

Mutual acceptance of such a relationship by the spouses, although conducive to compatibility, does not meet each partner's requirement for need satisfaction. It is natural to as sume then, that 
each spouse will seek this satisfaction through sources outside the marriage.

Most couples maintain relationships outside their marriage. Whether they be for career advancement, social acceptance, or kinship obligations, their importance lies in a mutual exchange of assistance and emotional support. This network of social relationships would not only serve to satisfy the needs of couples with author itarian ideological preferences but also those couples, despite a greater degree of marital $\mathrm{VA}$, who are unable to handle alone the burden of stressful situations.

Bott (1959) contends that the choice of social contacts is partially affected by personality. This implies that people choose to form relationships with others on the bases of personal needs which must be expressed for their satisfaction to be realized. In marriage, personal needs are more difficult to meet when they are unknown.

The frequency with which the people known by a family know and meet with one another independently of the couple indicates the extent to which a common set of needs are experienced and values are shared. This relative "connectedness" of the social network would then afford one or both spouses with an objective, predictable source of support as well as a channel for self-expression. The availability of such a resource would seem to limit the need for 
marital partners to structure their positions in relation to each other. We, therefore, hypothesize that:

Hypothesis III. The greater the connectedness of a couple's social network, the less will be the marital VA.

This element of connectedness in the social network denotes a type of esprit de corps or group identification for those involved. The likelihood that each person shares similar ideas, values, and attitudes suggests that there would be less occasion for feeling anxious by self-exposure or feeling threatened by opposing views because these would exist only at a minimal level. In fact, depending upon the nature and function of the group, its membership may lean toward the complete exclusion of persons not sharing the same values.

As previously mentioned, ingroup-outgroup cleavages typify the authoritarian person's response to his environment and thus his choice of associates. He is most likely to form relationships only with those who share the same rigid, externalized set of values. The restrictedness of the se relationships would facilitate the formation of a larger, more complex and fully integrated network of the se relationships.

We, therefore, hypothesize that:

Hypothesis IV. The greater the connectedness of a couple's social network, the greater will be the spouses' combined AFI. 
These hypotheses suggest some preliminary relationships between three specific variables. They provide a basis for investigating the study's basic as sumption which holds that personal dispositions of the marital partners in combination with the social context of their marriage affect the spouses' attitudes toward verbal communication with one another. Data relevant to these variables can be used then in the characterization of specific marital patterns. 


\section{CHAPTER III}

\section{METHODOLOGY}

\section{INTRODUCTION}

In the early stages of this study, we selected and hypothesized relationships between the following three variables: the social-psychological variable of the individual's and the couple's attitudes toward verbal communication, verbal accessibility (VA); a personality variable, authoritarian family ideology (AFI); and, the social variable of the connectedness of the couple's social network (SN).

\section{SELECTION AND CONSTRUCTION OF INSTRUMENTS}

In order to examine the hypothesized relationships between these variables, we decided to administer a battery of instruments which would include the following: (1) a personality measure; (2) a measure of VA, with three target persons; (3) a measure of social network; and (4) some miscellaneous identifying data.

A scale developed by Jane Loevinger (1962), "Authoritarian Family Ideology" (AFI), was chosen to measure the personality variable of authoritarianism in our subjects. Although Loevinger's scale had been validated only for female subjects, we also administered it to the male subjects. In addition to this scale, we utilized a related 
instrument, "Rejection of Women's Biological Role" (RWBR), which we also administered to all the subjects. We titled both of the se scales "Family Problems Survey" when administering them to the subjects. See Appendix.

To measure the social-psychological variable of VA, we made certain adaptations in the instrument developed by Sidney M. Jourard and Paul Lasakow (1958), "The Self-Disclosure Questionnaire." The instrument, as constructed and administered by Jourard and Lasakow, consisted of sixty items broken into groups of ten. Each group of ten dealt with one of six general categories of information about the self: attitudes and opinions, tastes and interests, work or studies, money, personality, and body. Subjects were asked to disclose, according to the self-disclosure rating scale included on the questionnaire, how much they had talked to each of five target persons about a specific item. Target persons are "persons to whom information about the self is communicated," and included mother, father, female friend, male friend, and spouse. To adapt this questionnaire to our purposes, we first reduced the number of items on the scale from sixty. to forty-two, removing three items from each of the six categories. We selected as the criteria for removal of items those which were least specific and/or least meaningful according to a consensus of opinion by the researchers. Next, we reduced the number of target persons from five to three: parent (subject was asked to select one), 
best friend (subject was asked to identify his best friend), and spouse. We thus reduced the original instrument in order to avoid tiring our subjects. A third change in Jourard and Lasakow's self-disclosure rating scale was made in the wording, to transform it into an attitudinal scale. The original instrument was designed to measure the extent to which the subject had made his attitudes known to other persons. Because we were interested in the subject's attitude toward communication as opposed to his actual communication, we changed the scale's response categories from "Have told . . . " to read "Would tell . . . " or "Would talk..." We called this instrument the "Interaction Survey" when administering it to the subjects. See Appendix.

We were unable to find an instrument which measured the connectedness of a couple's social network (SN) and it was therefore necessary to construct one. This instrument was entitled "Family Friends Survey." See Appendix.

In order to collect general information about the sample, a "General Information Sheet" was worked out and added to the battery of instruments. It was used to collect data about occupation, age, level of education, duration of marriage, number of children in the family, and the number of years the subjects had lived in their present community. See Appendix. 
III. THE SAMPLE

Our primary considerations in the selection of a sample were size and accessibility. Through group consensus, we decided on a sample size of fifty couples. Primarily because of their availability and ability to readily comprehend the instructions for the instruments, we chose couples from the married graduate students attending the School of Social Work (SSW), Portland State University, during Fall Term, 1968. We were aware that in choosing students from the SSW as our sample, there would be some biasing influence of students studying students. However, we attempted to counteract some of the bias by selecting questionnaires, for example, rather than interviewing our subjects. Confidentiality of all material collected was also stressed, and this was in part achieved by coding the instruments. All of the couples, a total of seventy, were sent a letter requesting their participation in our research study. See Appendix. To collect the data from a sample of fifty couples, each of the five researchers administered the instruments to ten couples. In preparation for this, each researcher was given a list of thirteen SSW students and their spouses, and there was a reserve list of five couples. This allowed for those couples who were either unwilling or unable to participate in the survey. Twenty of the couples contacted fell into this latter category. 


\section{THE PRETEST}

Before administering the questionnaires to the sample, each researcher was asked to pretest the set of three instruments on at least one couple. Prior to doing this, a preliminary set of instructions was worked out and given to each researcher in order to promote uniformity in the administration of the instruments.

The purpose of the pretest was to familiarize the researchers with the instruments and their administration, to point out any technical errors in construction and/or duplication of the instruments, and to acquaint the researchers with possible questions that might be asked by the subjects as well as special conditions that might prevail, in order that these could be handled uniformly by all researchers.

Results of the pretest included correction of technical errors on the instruments, revision of the set of instructions given to the researchers, group discussion of questions raised and problems encountered during the pretest, and familiarization of the researchers with the administration of the instruments. It was also found during the pretest that reading the instructions aloud with the subjects, plus having them complete sample items gave the most satisfactory results. 


\section{COLLECTION OF THE DATA}

Each couple included in the sample was contacted by telephone about a week after receiving our letter. The telephone contact served to determine their willingness to participate in the project, to reiterate the general purpose of the study and the confidentiality of all information collected, and to set up a time when a researcher could administer the instruments to the couple. In all but two cases, the instruments were administered in the couple's home. It took approximately three weeks for all of the data to be collected. See

"Format for Phone Contact" and "Format for Home Contact" in the Appendix. The total time required to complete all three instruments varied from forty to eighty minutes. Upon completion, the coded instruments were checked for completeness:by the researcher administering them and were then placed in an unmarked envelope to ensure confidentiality.

\section{DESCRIPTION OF THE SAMPLE}

Information which was gathered from the "General Information Sheet" filled out by each individual in the sample allows for the following general description of the fifty couples (one-hundred individuals).

Half (fifty) of the subjects in our sample were graduate School of Social Work students at Portland State University. Twenty-eight 
of these were first year graduate students and twenty-two were second year; twenty-five of the se were female students, and twentyfive were male students. Of the other half (fifty) of the sample, spouses of the SSW students, fifteen were not employed. This number included both housewives (nine) and spouses who were themselves students (six). Of the thirty-five spouses who were employed, eight were employed in social work and related fields. Of the remaining twenty-seven employed spouses, occupations for women ranged from Home Economist to Secretary, and for men occupations ranged from Attorney to Truck Driver.

Ages of the subjects ranged from 22-62 years, and the mean for the whole population was 33 years. Level of education for the sample ranged from two years of high school to ten years of education subsequent to completion of high school, which might include any combination of college, business and/or professional education. The mean years of education for the whole population was 16.07 (using the first year of grade school as year one, etc.). The mean for SSW students was 16.62 years of education; for spouses the mean was 15.52 years (for male spouses the mean was 16.22 years; for female spouses the mean was 14.83 years.)

For the couples in the sample, the duration of marriage ranged from 7 months to 32 years, with a mean of 9.5 years. The number of children per family ranged from $0-7$, with a median of 2 children 
per family.

With regard to the length of time the subjects had lived in their present community, the range for the whole population was 2 months to 41 years (for husbands, the range was 2 months to 30 years; and for wives, the range was 2 months to 41 years). The mean for the whole population was 6.7 years (for husbands, the mean was 6.2 years; and for wives, the mean was 7.2 years). The median was 3 years for the whole population (3.1/2 years for husbands and 3 years for wives). See Table I.

\section{SCORING THE DATA}

The score sheet for scoring the responses on the "Family Problems Survey" (AFI and RWBR) was already available. Scoring of this instrument was accomplished by indicating on the score sheet those responses made by the subject corresponding to the keyed responses making up the scales. These responses were then totaled giving an AFI score and a RWBR score. The possible range for AFI scores was $0-45$, and the possible range for $R W B R$ scores was $0-11$.

It was necessary to construct a score sheet for tabulating the responses on the "Interaction Survey" (VA). Individual VA scores were computed by summing the responses for each of the three tar get persons and then adding the three totals. Couple VA scores were computed by multiplying the corresponding item responses in the 


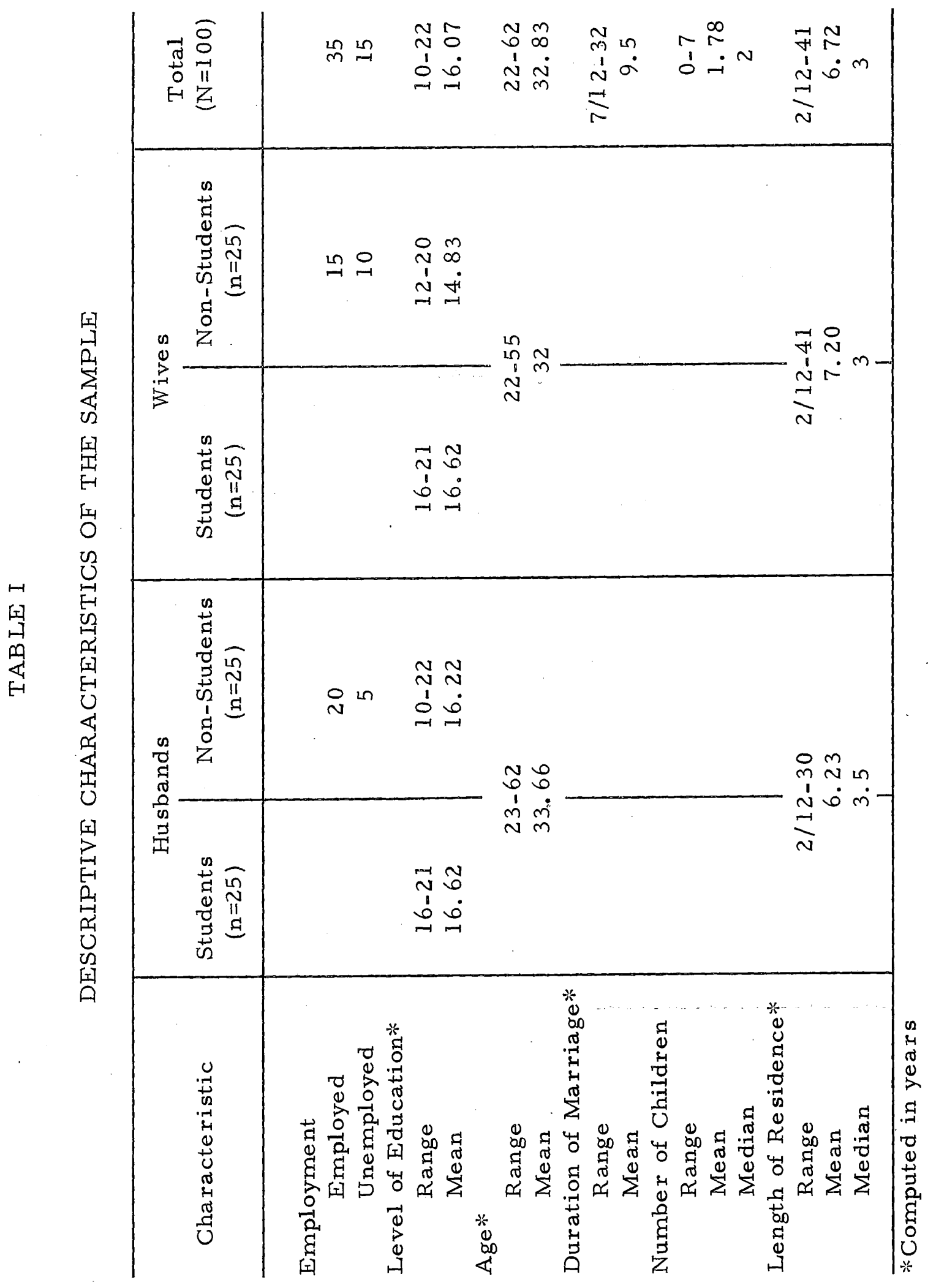


spouse column of the husband with the spouse column of the wife, and summing the total. It was felt that the multiplication of the se scores would allow for the interaction effect of the willingness of the spouses to communicate with one another. The possible range for individual VA scores, thus, was 0-252, and for couple VA scores 0-168. Scoring the "Family Friends Survey" (SN) was accomplished by totaling the number of connecting lines drawn in Column III by the couple. This score was recorded on the instrument itself. The possible range for SN scores was 0-10. See the Appendix for copies of the score sheets.

Tabulation of the data was done by all the researchers, working in pairs. Each researcher worked independently, and the results were then checked by the other member of the pair. All the data were then checked for accuracy, in preparation for the statistical analysis which is covered in Chapter IV. 
CHAPTER IV

\section{FINDINGS}

\section{DATA ANALYSIS}

This study was based on fifty graduate social work students and their spouses. All married couples in the School of Social Work at Portland State University were invited to participate. As the sample was not randomly selected, one must be cautious in generalizing from the results of this study. The sample size gave an $\mathrm{N}$ of 50 for investigating the variables as they related to the marital unit, and an $\mathrm{N}$ of 100 in examining the variables on an individual basis.

Three instruments were used to collect data. The "Family Problems Survey" was used to measure the personality variables of authoritarian family ideology (AFI) and rejection of woman's biological role (RWBR). The second instrument, "Interaction Survey," was used to appraise the social-psychological variable, verbal accessibility (VA). The third instrument, "Family Friends Survey," was used to assess the social variable, connectedness of the couple's social network (SN). The first two instruments were completed on an individual basis, while the third one was responded to jointly by both spouses. See Table II for descriptive data.

The data were analyzed separately for male social work 
TABLE II

\begin{abstract}
RESULTS OF TEST SCORES ON AUTHORITARIAN FAMILY IDEOLOGY (AFI), REJECTION OF WOMAN'S BIOLOGICAL ROLE (RWBR), VERBAL ACCESSIBILITY (VA), AND SOCIAL NETWORK (SN)
\end{abstract}

\begin{tabular}{lccrrr}
\hline Scale & $\begin{array}{l}\text { Number } \\
\text { of Cases }\end{array}$ & Range & Mean & Variance & $\begin{array}{r}\text { Standard } \\
\text { Deviation }\end{array}$ \\
\hline AFI & 100 & $2-28$ & 12.46 & 45.16 & 6.72 \\
RW BR & 100 & $0-8$ & 3.34 & 3.87 & 1.97 \\
VA & 100 & $89-252$ & 184.01 & $1,413.65$ & 37.59 \\
SN & 50 & $0-10$ & 1.7 & 4.25 & 2.06 \\
\hline
\end{tabular}

students, female social work students, male non-students, and female non-students. It was discovered that there were two couples where both the husband and wife were graduate social work students. In order not to contaminate the groups, these two couples were left out. This left 48 couples or 96 individuals. The wife was the student in twenty-four of the couples and the husband was the student in the remaining 24 couples. The AFI and VA scores for these four groups were compared. See Table III.

The AFI data in Table III indicates that female social work students have a lower mean than the male social work students, male non-students, and female non-students. However, before concluding this, it was necessary to test the difference statistically and this was accomplished by using $t$ tests. 
TABLE III

AFI AND VA SCALE DATA BY SEX AND STUDENT STATUS

\begin{tabular}{llrrrr}
\hline \multicolumn{1}{c}{ Group } & Scale & \multicolumn{2}{c}{ Male } & \multicolumn{2}{c}{ Female } \\
& & Mean & $\begin{array}{c}\text { Standard } \\
\text { Deviation }\end{array}$ & Mean & $\begin{array}{c}\text { Standard } \\
\text { Deviation }\end{array}$ \\
\hline Student & AFI & 13.08 & 6.85 & 7.96 & 3.40 \\
Non-Student & AFI & 14.75 & 7.08 & 14.04 & 7.13 \\
Student & VA & 186.08 & 39.17 & 187.17 & 33.19 \\
Non-Student & VA & 182.88 & 42.33 & 175.08 & 34.98 \\
\hline
\end{tabular}

Before calculating and evaluating the $\underline{t}$ tests, a test for homogeneity of variance was conducted. Using the $F$ test in a two-tailed test at the .05 level of probability, the female student group's variance was found to be heterogeneous when compared with the other groups. In testing the groups which have a hete rogeneous variance with equal N's, the number of degrees of freedom were calculated using $1 / 2$ the number of degrees of freedom used where the groups have homogeneous variances (Edwards, 1960). See Table IV.

In examining the data in Table III in relation to VA, the means of the four groups appear relatively equal to each other. Using the $F$ test to evaluate the homogeneity of variance, all four of the group's variances were found to be homogeneous at the .05 level of probability. In testing the means, $\underline{t}$ tests failed to indicate significant differences in these scores. See Table V. The lack of differences between 
TABLE IV

t TESTS OF AFI SCALE DATA BY SEX AND STUDENT STATUS

\begin{tabular}{lrlll}
\hline \multicolumn{1}{c}{ Group } & Mean & Variance & $\begin{array}{l}\text { Standard } \\
\text { Deviation }\end{array}$ & t \\
\hline Male Student & 13.08 & 46.91 & 6.85 & $3.21 * *$ \\
Female Student & 7.96 & 11.54 & 3.40 & \\
Male Non-Student & 14.75 & 50.19 & 7.08 & 0.34 \\
Female Non-Student & 14.04 & 50.79 & 7.13 & \\
Female Student & 7.96 & 11.54 & 3.40 & $3.70 * *$ \\
Female Non-Student & 14.04 & 50.79 & 7.13 & \\
Male Student & 13.08 & 46.91 & 6.85 & 0.33 \\
Male Non-Student & 14.75 & 50.19 & 7.08 & \\
Male Student & 13.08 & 46.91 & 6.85 & 0.46 \\
Female Non-Student & 14.04 & 50.79 & 7.13 & \\
Female Student & 7.96 & 11.54 & 3.40 & $4.15 * *$ \\
Male Non-Student & 14.75 & 50.19 & 7.08 & \\
\hline
\end{tabular}
a Each group consists of 24 cases
$* * * \quad \mathrm{p}<.01$

the four groups is of interest. Perhaps the high similarity in socioeconomic factors between the four groups influenced the results. The test may have not been discriminating enough to diffe rentiate actual existing differences. It is clear further work would be needed to investigate the meaning of the se results. 
TABLE V

t TESTS OF VA SCALE DATA BY SEX AND STUDENT STATUS

\begin{tabular}{lcccc}
\hline \multicolumn{1}{c}{ Group } & Mean & Variance & $\begin{array}{c}\text { Standard } \\
\text { Deviation }\end{array}$ & t $^{\mathrm{b}}$ \\
\hline Male Student & 186.03 & $1,534.26$ & 39.17 & .10 \\
Female Student & 187.17 & $1,101.58$ & 33.19 & \\
Male Non-Student & 182.88 & $1,791.78$ & 42.33 & .68 \\
Female Non-Student & 175.08 & $1,223.42$ & 34.98 & \\
Female Student & 187.17 & $1,101.58$ & 33.19 & 1.20 \\
Female Non-Student & 175.08 & $1,223.42$ & 34.98 & \\
Male Student & 186.08 & $1,534.26$ & 39.17 & .26 \\
Male Non-Student & 182.88 & $1,791.78$ & 42.33 & \\
Male Student & 186.08 & $1,534.26$ & 39.17 & 1.00 \\
Female Non-Student & 175.08 & $1,223.42$ & 34.98 & \\
Female Student & 187.17 & $1,101.58$ & 33.19 & .38 \\
Male Non-Student & 182.88 & 1.791 .78 & 42.33 & \\
\hline
\end{tabular}

a Each group consists of 24 cases

b None of the values were significant

\section{CONSENSUS OF HUSBAND'S AND WIFE'S RESPONSES}

It was decided to investigate the degree of similarity of hus band's and wife's scores on the AFI, RWBR and VA scales. This exploration was accomplished by correlating each husband's score on the AFI, RWBR, and VA scales with his wife's corresponding score. The three sets of scores were correlated using the Pearson 
Product Moment Correlation technique. See Table VI. From the se results it can be seen that the spouses in the sample were similar in their responses but not to a high degree.

TABLE, VI

CORRELATIONS BETWEEN HUSBAND'S AND WIFE'S RESPONSES ON AFI, RWBR, AND VA SCALES

\begin{tabular}{lcc}
\hline Scale & Number of Cases & Correlations \\
\hline & 50 & $.29 *$ \\
AFI & 50 & $.45 * *$ \\
RWBR & 50 & $.30 *$ \\
VA & & \\
\hline
\end{tabular}

$$
\begin{aligned}
* \mathrm{p}<.05 \\
* * \mathrm{p}<.01
\end{aligned}
$$

\section{RELATIONSHIP BETWEEN AFI AND RWBR SCORES}

The relationship between the individual's scores on the AFI and the RWBR was first examined by correlating the husband's AFI score with his RWBR score. A coefficient of $r=.44$ was obtained which was statistically significant at the .01 level of probability. Then the wife's AFI score was correlated with her RWBR score which produced a coefficient of $r=.29$ and was statistically significant at the .05 level of probability. Using Fisher's $\mathrm{Z}$ transformation, the two correlation coefficients were tested to see if they were significantly different. The coefficients were found not to be significantly different 
at the .05 level of probability. Thus, the husbands did not display a significantly stronger relationship between these two variables than did their wives.

\section{HYPOTHESIS TESTING}

Correlation was used for statistical analysis of the hypotheses. The Pearson Product Moment Correlation Coefficient method was chosen in preference to other correlation techniques because of its smaller standard error and greater reliability. Individual and couple scores were correlated as necessary to test each hypothesis.

Hypothesis I stated, "the greater an individual's authoritarian family ideology (AFI), the less will be his verbal accessibility (VA)." Each individual's score on the AFI instrument was correlated with each individual's score on the VA instrument. The null hypothesis which assumes that there is no relationship between the individual's AFI and VA scores was tested. A value equal to or exceeding \pm .197 for "r" indicates statistical significance at the .05 level with 98 degrees of freedom and two variables. Calculations produced a significant but low correlation coefficient of $r=-.21$, thus rejecting the null hypothesis, and accepting the alternate hypothesis that an inverse relationship exists between the individual's AFI and VA.

Hypothesis II states, "the greater a couple's AFI, the less will be the marital VA." The elaboration of Hypothesis I was developed 
in order to explore the relationships between AFI and VA in the marital unit. The couple's AFI score was arrived at by arithmetically summing the AFI scores of the husband and wife. In obtaining a marital VA score, a special consideration was incorporated into its enumeration. It was believed that the interactional aspect of $\mathrm{VA}$ should be taken into account in the marital VA score. This was accomplished by multiplying each of the husband's item responses under the column labeled Spouse in the VA instrument by each of the wives corresponding responses, and then summing these resulting values for all items. This summation then represented the couple's marital VA. The couple's AFI score was then correlated with their marital VA score.

The computation resulted in a statistically significant correlation coefficient of 0.39 . A value equal to or greater than \pm .36 was required to be significant at the .01 level with 48 degrees of freedom and two variables. Hence, the null hypothesis was rejected and the alternate hypothesis was accepted, i. e., an inverse relationship exists between the couple's AFI and marital VA.

Later, the procedure in which the marital VA score was calculated was re-examined. The question was raised whether the correlation results would be different if instead of calculating the marital VA score in the manner described above, the scores were to be constructed simply by summing the husband's and wife's 
responses. It was decided to correlate the couple's AFI score with a new set of marital VA scores arrived at by using this simple addition method.

Computing the Pearson Product Moment Correlation Coefficient with these new scores produced a value of $r=-.36$. This correlation was found to be statistically significant at the .01 level with 48 degrees of freedom and two variables. Thus, in using this simple addition method in calculating the marital VA scores, the null hypothesis was still rejected. See Table VII.

TABLE VII

CORRELATIONS BETWEEN AFI AND VA SCALE DATA BY INDIVIDUALS AND COUPLES

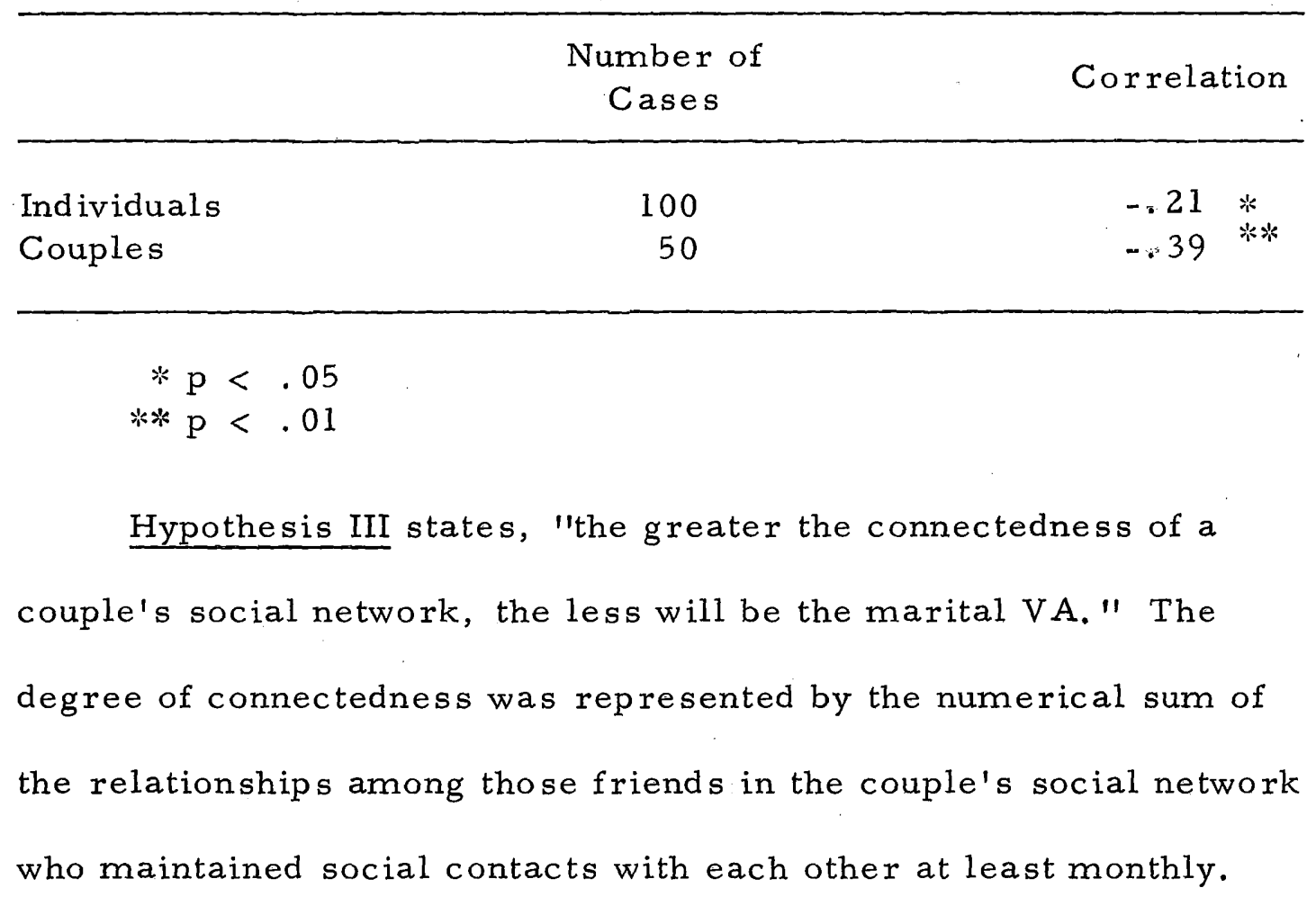


The marital VA score was calculated in the same manner as described for Hypothesis II. The social network scores were then correlated with the couples' marital VA scores. These marital VA scores were calculated using the multiplication method.

The resulting correlation coefficient had a value of $r=.07$. Based on 48 degrees of freedom and two variables, a value of \pm .28 or greater was required to achieve significance at the .05 level. The coefficient was not significant and the null hypothesis of no relationship between the se two variables was accepted.

Hypothesis IV states, "the greater the connectedness of a couple's social network, the greater will be the spouses' combined AFI." The spouses' combined AFI score and the connectedness of their social network score were derived at as defined in testing Hypothesis II and Hypothesis III respectively. The two sets of scores were then correlated.

The computations produced a correlation coefficient of $r=.09$. As in Hypothesis III, the coefficient had to equal or exceed a value of 土. 28 to be significant at the .05 level with 48 degrees of freedom and two variables. The null hypothesis was accepted since the coefficient was not significant. The hypothesis that there is an inverse relationship between the connectedness of the couple's social network and the spouses' combined AFI was not supported.

There are some reasons for suspecting the validity of the social 
network instrument. The instructions stated that spouses were to respond jointly. However, it was observed that in many cases one spouse would take a dominant role in completing the form with little genuine consultation with the other spouse. Also, in several other cases where disagreement arose between spouses, it was noted that a compromise evolved in responding to the instrument. It was felt that in cases where one spouse monopolized the decision-making process or where the couple had to compromise in responding, the results may have been seriously distorted. From the experience gained in constructing and administering this instrument, it was felt that a more precise measurement might result if instruments were designed for each spouse to respond to individually, and a method of scoring representing a composite of the results be developed. 


\section{CHAPTER V}

\section{CONCLUSIONS}

\section{DISCUSSION OF FINDINGS}

This study was concerned with marital interaction. It addressed itself to three specific variables affecting adult socialization, the personality development of each marital partner, and the quality and character of the marriage.

Fifty social work students and their spouses made up the sample. Based upon a review of the literature and other research, it was surmised that the structure of a marriage would appear more conventional where the couples displayed a combination of high authoritarian family ideology (AFI) and low verbal accessibility (VA) scores and had close-knit social networks. Conversely, it was felt that marriages in which couples displayed a combination of low AFI and high VA scores, and had loose-knit social networks would appear less rigid and conventional. See Table VIII.

The results supported the first two hypotheses. Using the Pearson Product Moment Correlation technique for data analysis, moderately low correlations between the variables were found, How ever an inverse relationship between individual adherence to AFI and VA was established and accepted as substantiating the hypotheses. 
This same relationship was established between the couples' adherence to AFI and marital VA.

Adorno, et al. (1950) points out that people with a high degree of authoritarian personality orientation utilize many ego defenses in order to maintain a moral facade, but that they do so at the expense of self-expression and emotional release. They seemingly experience a strong need to hide their personal selves from exposure to others. Reflecting a rather strong opinion, Jourard (1959a) contends:

Every maladjusted person is a person who has not made himself known to anothe $r$ human being, and in consequence does not know himself . . . he struggles actively to avoid becoming known to another human being. He works at it ceaselessly, twenty four hours daily, and it is work! (p. 503).

TABLE VIII

A MARITAL TYPOLOGY

I. Low AFI

Personality

Variable

Social-psychological Variable

Social Variable

High VA
Low VA

II. High AFI

Loose-knit Close-knit Social Network

It should be emphasized that while studies conducted by Adorno, and others, have been concerned with contrasting the extreme forms 
of authoritarian and equalitarian types, we did not anticipate in our study such extremes. Rather, we were interested in a lesser variation of these personality concepts.

Writing in connection with the relationship-focused approach to marital problems and the beneficial results of increased selfdisclosure, Bardill (1966) makes this observation:

As each partne $r$ increases his reality-based sensitivity to the situation, the ego gains in strength and it may be postulated that a strengthened ego is better able to perceive the irrational aspects of earlier life conflicts for which resolution is sought in the present. Just as the healing of a wound is a natural function of the human body, so is the integration of new insights a normal function of the ego. This approach makes use of an understanding of the interactional dimension of the marital relationship-the forces that are affected by the interaction of the marital partners. Such an approach utilizes the increasing awareness of the continuing nature of personality development--the unique needs that must be met at every stage of life--and recognizes the concept that a marriage relationship has stages of development in which crucial needs must be met for the relationship to progress (p. 77).

To be a continuing growth process, marriage probably requires a commitment by the marital partners to mutual, reciprocal involvement in their relationship. Such involvement demands of each partner a continuous effort to solve the problems characteristic of each developmental stage. The degree of success with which the couple works together to meet the se tasks would provide some clues concerning the quality characterizing the dynamics of their relationship. Presumably vital to this interactional process is the readiness 
of the partners to communicate verbally with each other about important attitudes and feelings.

Research, in the main, has pointed in the direction of women being "better" self-disclosers than men (Jourard and Lasakow, 1958, and Jourard, 1959b). This may be due to the more expressive roles women are taught to assume in our society which call for especial concern with, and responsiveness to, feelings. Men, on the other hand, are taught to adopt more instrumental roles which sometimes encourage the suppression and distrust of feelings and shift the basis of personal transactions to more cognitive factors (Parsons and Bales, 1955).

The results of this study, however, failed to reveal any significant sex-related differences for self-disclosure rates. Several factors may have contributed to this outcome. First, the sample was not representative of the general population. Its participants were drawn from a specified group of individuals displaying rather homogeneous characteristics. Generally speaking, they all shared a common urban, middle-class orientation. It is generally recognized that men of this background do not view emotional expressiveness as inappropriate behavior. It was not unexpected then that the discrepancy between self-disclosure scores for the sexes would be less where men and women shared similar attitudes about personal expressiveness. Then too, half of the sample consisted of 
individuals aspiring toward a profession which places considerable value upon the communication of attitudes and feelings. These characteristics of the sample may have biased the results of the study.

Second, the attempt to change the self-disclosure rating scale from a behavioral to an attitudinal measure may have influenced the findings. One could reason that where no provision was made to determine the validity of individual statements, respondents might tend to evaluate and present their capacities at a level more indicative of that aspired to rather than actually achieved. The capacity to express oneself openly is generally regarded as reflecting an emotionally mature and stable personality. It is natural to as sume that respondents to the questionnaire would wish to present themselves in this light. That each participant responded individually to the questionnaire may have served to reduce the actual disparities in self-disclosure rates which theorists claim to exist between the sexes.

Several other relationships became apparent in our study. First, relative to both $\mathrm{AFI}$ and VA scores, the data reflected some similarity between the responses of husbands and wives. The degree of consensus however was not high and its significance lies more in its agreement with the findings of other studies (i. e. Byrne and Blaylock, 1963, and Levinger and Breedlove, 1966). The Levinger and Breedlove study not only establishes that spouses tend to be similar 
in certain important attitudes but suggests that this agreement is useful as an index of marital satisfaction. Based on this study, we might surmise then that the couples in the present sample have reasonably satisfactory marriages. In terms of marriage as a dynamic process, we could as sume that these couples reflect adequate task performance in their marriage at its particular developmental stage. Second, the relationship between AFI and RWBR (rejection of women's biological role) scores for individuals was statistically significant. Implications for the authoritarian personality are numerous in this respect. Adorno, et al. (1950) state that the tendency to exaggerate sex roles is characteristic of the rigid personality. Individuals with this orientation view themselves in terms of features assigned specifically to their sex. The fulfillment of masculine and feminine roles then are realized only through channels deemed appropriate for each sex and defined in terms of a dominantsubmissive relationship. Any transference of personality traits between the sexes or departure from one's strictly defined role violates this premise, and those persons deviating from the se norms are considered weak and/or contemptible.

Five of the eleven items in the RWBR cluster deal with two of the weakest and most vulnerable periods of a woman's life: pregnancy and childbirth. Two more consider the emotion-laden experience of nurturing an infant, and another questions women's interest 
in sexual gratification. In each of the se instances the female is portrayed as having little control over her subordinate position. She is in a susceptible state by virtue of another's actions. We would assume then that authoritarian personalities, having a tendency to identify with the strong and assertive, would find people in situations such as these to be contemptible. Consequently they would be more likely to score higher on the RWBR scale than would the less rigid person. The results of this study supported this assumption.

We further speculated that authoritarian males would score higher on RWBR scale than would their female counter-parts. The basis for the reasoning here was the depersonalized regard with which authoritarian men generally approach women and conduct their intimate relationships with them. However this contention was not substantiated. It is believed that this was partially due to the disproportionate number of respondents obtaining low or mode rately low scores on the AFI scale. The sample did not provide a range of scores that was varied enough or apparently high enough to test this as sumption.

Time did not allow for the statistical analysis of all the raw data. Nonetheless several untested observations seem worthy of mention. With few exceptions, subjects indicated that they would reveal more of themselves to their spouses than to either of the other two target persons. This supported the findings of Jourard (1961) and 
Kresse, et al. (1967). Two particular attitudinal areas where some subjects tended to have the lowest VA were those relating to sex and money. In a few cases it was noted that the respondents would talk more to a closest friend regarding these topics than to their spouses. In view of the importance which viable communication patterns have for the marital relationship, such deviations may be reflective of some pathology within the marriage of the se particular respondents. The third and fourth hypotheses of the study were derived from Bott's (1959) work relative to two kinds of social networks and familial role relationships. Briefly, we hypothesized that (1) "the greater the connectedness of a couple's social network the less will be the marital VA," and (2) "the greater the connectedness of the couple's social network, the greater will be the spouses' combined AFI."

We had reasoned that the individual tends to seek out others with similar determinant attitudes: persons who support his attitudes. Where communication patterns were restricted among spouses we assumed that supportive relationships outside the marriage would be sought for need fulfillment. In addition, we speculated that the accessibility of friends would further reduce the likelihood that the se spouses would rely upon one another for support by making available to them a predictable source of assistance as well as a channel for self-expression. For the more conventionally structured marriage, this situation would tend to be characterized by more authoritarian 
personalities, having low marital verbal accessibility and a closeknit social network. However, the results did not support this reasoning and the hypotheses were not substantiated. Perhaps the defense mechanisms employed by the authoritarian personality provide adequate support themselves. Communication with others outside the marriage then may not necessarily be in order when marital $\mathrm{VA}$ is low.

In a study with similar hypotheses, Nooney and Polansky (1962) addressed themselves to the relationship between authoritarianism and the degree of perceived similarity in others as these two factors jointly influence VA. Their results revealed an inverse relationship of statistical significance: authoritarian individuals were found to be less verbally accessible with persons holding similar attitudes, than with those having dissimilar attitudes. This they felt was in agreement with clinical experience:

We know that whereas many people are encouraged by simple acceptance to "open up", those with a conventionalized, rigid stance need more than just a reduction of restraints. They seem to require an incitement-either in the service of self-justification or in the pleasure of expressing their unconscious negativism, and opposition (p. 41).

The absence of substantiating data to support the last two hypotheses may have also been affected by the instrument used in measuring the couple's social network. Its lack of sophistication and precision raises the question of its validity. 
A third factor to consider is the sample group itself. Many of the subjects were, to varying degrees, in transitional states in their life space. Some were experiencing the upsets of moving to the Portland metropolitan area. Approximately one fourth of the subject group was beginning its graduate studies and another fourth was returning for its second year. Most were faced with the dilemmas accompanying new role adjustments. Responsiveness to interaction may vary from one period in a person's life to another, and differences may also be linked to corresponding differences in a subject's contemporary experiences (Rickers-Ovsiankina and Kusman, 1958, and Nooney and Polansky, 1962).

\section{THEORETICAL CONSIDERATIONS}

Marriage which takes place between two personalities and within a social situation is in essence a relationship. It is not just personal but interpersonal and interactional in nature. "In an analysis of the dynamics of marriage, two factors need consideration: the persons and the marriage, the characteristics of the individuals involved and their interaction in the marriage" (Stone and Levine, 1965 , p. 277). It was the primary aim of the study reported here to focus upon the interpersonal and interactional aspects of this social institution and to assess associations, not causative factors, between several variables. 
The tremendous influence and importance that marriage plays in the lives of most people is not to be underestimated. Not only immature individuals, but mature persons as well, caught in the web of marital strife and conflict often begin to show signs of personality maladjustment and deterioration.

Christensen (1950) asserts:

There is a two-way relationship between family stability and the health of family members. In one direction, it can be shown that if the husband and wife, and children are getting along with each other they are more likely to be healthy individuals; and, conversely, if they are in constant tension and conflict with each other they are more likely to become neurotic, or psychotic, or to develop physical illnesses that are psychosomatic in origin (p. 360).

It is probably safe to state that beyond the influence of parents upon the individual during childhood, no factor has a greater or more significant effect upon an individual's life than marriage. A marital partner is in a most strategic position to affect adult development in either a beneficial or a destructive way.

In our society and culture, considerable value has been placed on romantic love, and many men and women have come to regard it as the main basis for marriage. Too frequently potential marriage partners fail to really know one another prior to the marriage ceremony. They have, to varying degrees, married a facade without having achieved an interpersonal relationship reflective of an "I and thou" quality. At best, the courtship period cannot possibly reveal 
true character, the "real person," like the daily behavior of partners thrown together in the prolonged intimacy of marriage. And what proportion of married couples in America fail to ever achieve a reciprocal relationship of mutual self-disclosure?

Relative to this question, Jourard (1959a) as serts:

It's possible to be involved in a social group, such as a family or work setting, for years and years, playing one's roles nicely with the other members--and never getting to know the persons who are playing the roles. Roles can be played personally and impersonally . . . a husband can be married to his wife for fifteen years and never come to know her. He knows her as "the wife" (p. 502).

That mates often go through life without really knowing their spouses seems most unfortunate and not conducive to personal fulfillment. The amount of personal information that one person is willing to disclose to another appears to be an index of the "closeness" of the relationship, and of the affection, love, and trust that . prevails between two people. In more general terms, self-disclosure and cathexis for the other person may be said to be correlated. Evidence to support this proposition stems from both clinical observation and systematic research (Jourard, 1959b).

In contrast to less complex cultures, or even that of early American society, social changes have had, and are having a disturbing effect upon the traditional roles which men and women are expected to enact within the marriage relationship. A vitally 
important example of this has been the emancipation of women. As a result of women's emancipation, the early period of many modern marriages is one in which husband and wife maneuver and struggle for positions of advantage and control--attempting to define roles which were previously prescribed by the culture (Christensen, 1950). Their need is thus increased for successful interaction, and a high level of VA, within the marriage gestalt. Discrepancies between the spouses centering around areas of their respective value systems, attitudes, and sentiments need to be worked out. VA of the partners appears to be important in order to cope successfully with the resultant role confusion and to facilitate the re-establishment of their ego-identities.

An essential as sumption for conceiving marriage in the above manner is the notion that in its development the personality of each partner is subject to continuous variation. Foote (1963) alludes to marriage as a pair of intercontingent careers, not in the conventional sense of the term, but in the sense of the orderly development of the person within the context of his relationships with others over time. He argues that it is logical to speak of marriage, not as static, but as a developmental process; an evolution through the enrichment or impoverishment of interpersonal relations. As such, a marriage is not likely to stand still or continue unchanged for very long. Arrest in the development of either partner makes it vulnerable to 
breakdown. Mates are, ideally, agents of mutual development as they interact with one another. Not infrequently people find themselves in marriages which tend to promote or demote the process of socialization, or "becoming," using a term coined by Gordon Allport (1955).

This approach has valuable relevance in terms of treatment. A "good" marriage does not necessarily have as a prerequisite two neurosis-free individuals. The constructive and destructive elements and their continuation in the interaction are at least as critical to the ultimate balance or equilibrium attained in the marriage. It is possible to offer treatment for certain discordant marital situations, and to achieve substantial improvements in the se relations, without working through all the unconscious neurotic complications in each partner (Gomberg, 1961).

Nelson N. Foote (1963), who has conducted extensive research at the Family Center at the University of Chicago, is a strong proponent of the interpersonal and interactional approach to marriage. He contends that the stability of relationships among family members is more a matter of ordered interpersonal relationships than the particular characteristics or traits the individual possesses at the time of marriage. He describes marriage as a developmental process the stability of which is modified in time as the personality changes in family members and as members adjust to life's 
situations. This conception of marriage as a developmental process is a relatively new approach to this oldest of social institutions.

\section{IMPLICATIONS FOR FURTHER STUDIES}

The findings of this study are relevant to marital satisfaction. It was assumed that the more willing were spouses to express among themselves important attitudes and feelings the greater would be the intensity of their marriage relationship. However a qualitative measurement of marital satisfaction, or other measures of the emotional significance of marriage were not employed due to the researchers' proximity to the sample subjects. Future research could contribute a great deal by correlating these or similar findings with data obtained from marital satisfaction schedules or in-depth interviews of marital partners.

A related research project might concern itself with developing criteria for the prediction of marital success or failure. We suggest that the relationships between AFI and VA established in this study: be used as a basis for evaluating the development of the interactional process over an extended period. Divorce, separation, or the couple's involvement in conciliatory sessions could be utilized as criteria for varying degrees of deterioration in marriage.

Further investigation of the VA and AFI response categories for each marital partner would be valuable for assessing the 
interactional effect which spouses have upon one another as well as the total marriage relationship. We would conjecture that certain combinations of personality types in a marriage would define in part particular patterns of communication. The study conducted by Nooney and Polansky (1962) revealed that, in general, authoritarian personalities were more verbally accessible with individuals holding dissimilar attitudes than with those having similar attitudes. Future research might address itself to this finding in the context of an intimate marriage relationship.

Empirically, our sample group could be described, in general terms, as having low AFI and relatively high VA scores. The extent to which this typifies urban, middle-class marriages was not determined due to the absence of comparison groups. For comparative purposes then, it would be meaningful to test the hypotheses of this study with samples varying in socio-economic standing.

Finally, we would suggest that future research include additional assessments of the social context of marriage. It is recognized that the friends and relatives of marital partners do influence the marriage relationship, for instance as sources of emotional support and assistance, as confidents and the like. An adequate method of measuring the effect of persons outside the marriage would increase our understanding of the marital relationship. 


\section{BIBLIOGRAPHY}

Ackerman, Nathan W. "The Diagnosis of Neurotic Marital Interaction, "Social Casework, Vol. XXXV, April, 1954, 139-147.

Adorno, T. W., et al. The Authoritarian Personality. New York: John Wiley \& Sons, Inc., 1950.

Allport, Gordon. 1955. Becoming: Basic Consideration for a P sychology of Personality. New Haven, Connecticut: Yale University Press.

- 1960. Personality and Social Encounter, Selected Essays. Boston, Massachusetts: Beacon Press.

Bardill, Donald R. "A Relationship--Focused Approach to Marital Problems," Social Work, Vol. 11, July, 1966, 70-77.

Bott, Elizabeth. Family and Social Network. London: Tavistock Publications Ltd., 1959.

Bowlby, John. Maternal Care and Mental Health. New York: Schocken Books, 1966.

Burgéss, E. W., Wallin, P., and Shultz, G. D. Courtship, Engagement \& Marriage. New York: Lippincott, 1954.

Byrne, D., and Blaylock, Barbara. "Similarity and Assumed Similarity of Attitudes Between Husbands and Wives," Journal of Abnormal and Social Psychology, Vol. 67, 1963, 636-640.

Christensen, Harold T. Marriage Analysis. New York: Ronald Press Co., 1950.

Duvall, Evelyn M. Family Development. Chicago, Illinois: J. B. Lippincott Co., 1957.

Edwards, Allen L. Experimental Design in Psychological Research. New York: Rinehart \& Company, Inc., 1960.

Erikson, Erik H. 1959, "Identity and the Life Cycle," Psychological Issues, New York: International Universities Press, Vol. 1, $1-171$. 
. 1963, Childhood \& Society, 2nd Ed. Revised. New York: W. W. Norton \& Co.

Foote, Nelson L. "Matching of Husband and Wife in Phases of Development, "Sourcebook in Marriage and the Family. M. F. Nimkoff, ed., Boston, Massachusetts: Houghton Mifflin Co., 1963.

Goldfarb, W. "Emotional and Intellectual Consequences of Psychologic Deprivation in Infancy: A Re-Evaluation, "Psychopath-" ology of Childhood, Edited by Hoch, P., and Zubin, J., New York: Grune \& Stratton, 1955.

Gomberg, M. Robert. "Casework Treatment of Marital Problems," Neurotic Interaction in Marriage, Edited by Victor M. Eisenstein, Basic Books, 1961.

Hill, Reuben. "Generic Features of Families Under Stress," Crisis Intervention: Selected Readings, Edited by Howard J. Parad, New York: Family Service Association of America, 1965, 32-53.

Jourard, S. M. 1959a, "Healthy Personality and Self-disclosure," Mental Hygiene, Vol. 43, 499-507.

. 1959b, "Self-disclosure and other-Cathexis, " Journal of Abnormal Psychology, Vol. 59, 428-431.

- 1961, "Age Trends in Self-disclosure, "Merrill-Palmer Quarterly, Vol. VII, 191-197.

- 1964, The Transparent Self. Princeton, New Jersey:

C. Van Nostrad Co., Inc.

Jourard, S. M. , and Landsmar, M.J. "Cognition, Cathexis, and the 'Dyadic Effect' in Men's Self-disclosing Behavior," Merrill-Palmer Quarterly, Vol. VI, 1960, 178-186.

Jourard, S. M., and Lasakow, P. "Some Factors in Self-disclosure," Journal of Abnormal Social Psychology, Vol. 56, 1958, 91-98.

Kresse, Barbara F., et al. A Scale of Verbal Accessibility in Marriage. Portland State College School of Social Work, Master's thesis, 1967, 89 leaves. 
Levinger, George, and Breedlove, James. "Interpersonal Attraction and Agreement: A Study of Marriage Partners, "Journal of Personality and Social Psychology, Vol. 3, 1966, $\overline{367-372 .}$

Levinger, George, and Senn, David J. "Disclosure of Feelings in Marriage." Unpublished Research. Univer sity of Massachusetts.

Levinson, D. J., and Huffman, P.E. "Traditional Family Ideology and its Relationship to Personality, "Journal of Personality, Vo1. 23, 1955, 251-273.

Lidz, Theodore. The Person. New York \& London: Basic Books, 1968.

Loevinger, Jane. "Measuring Personality Patterns of Women, " Genetic Psychology Monographs, Vol. 65, 1962, 53-136.

Nooney, James B., and Polansky, Norman A. "The Influence of Perceived Similarity and Personality on Verbal Accessibility, " Merrill-Palmer Quarterly, Vo1. 8, 1962, 33-41.

Parsons, T., and Bales, R. F. Family Socialization and Interaction Process. Glencoe, Illinois: The Free Press, 1955.

Personality in Nature Society \& Culture. Edited by Clyde Kluckhohn and Henry A. Murray. New York: Alfred A. Knopf, 1953.

Polansky, Norman A. "The Concept of Verbal Accessibility," Smith College Studies in Social Work, Vol. 36, October, 1965, $1-48$.

Rapaport, David. Organization and Pathology. New York: Columbia University Press, 1951 .

Rickers-Ovsiankina, Maria A., and Kusman, Arnold A. "Individual Differences in Social Accessibility, "Psychological Reports, Vol. 4, 1958, 391-406.

Spitz, R. "Ho spitalism, "Psychoanalytic Study of the Child, New York: International Universities Press, Vol. 1, 1945. 
Stone, Abraham, and Levine, Lena. "The Dynamics of the Marital Relationship, "Marriage \& Family in the Modern World: A Book of Readings, Edited by Ruth S. Cavan, New York: Thomas Y. Crowell Company, 1965.

Stryker, Sheldon. "Symbolic Interaction as an Approach to Family Research, " Marriage and Family Living, Vol. 21, 1959, $111-119$.

Sullivan, Harry Stack. Concepts of Modern Psychiatry. Washington: William Alanson White Psychiatric Foundation, 1946.

Teicher, Morton I. "Man in Society," Social Casework, Vol. 40, October, 1959, 442-444.

Walker, Patricia, et al. Verbal Accessibility Between Marital Partners As Studied In A Court of Domestic Relations. Portland State College School of Social Work, Master's thesis, 1968,112 leaves. 
APPENDIX 
FORMAT FOR PHONE CONTACT

1. Introduce self and your association with the thesis group.

2. "Did you receive our letter inviting you and your husband/wife to participate in our survey?"

"Do you have any questions concerning the survey?"

"The questionnaires deal with general attitudes and opinions about family living. Because of our association with the school, we are taking special precautionary measures to ensure confidentiality. Actually this thesis project is a continuation of a series of studies carried out by graduate students at the school."

"The questionnaires will take a little over an hour to complete and can be taken in your home at a convenient time. What would be a convenient time for you?"

3. Arrange a time.

4. Ask for directions to the home if you are unfamiliar with the area.

5. Leave your phone number in case they are unable to keep the appointed time.

\section{FORMAT FOR HOME CONTACT}

\section{(NOTE TO INTERVIEWER)}

If the appointment was made more than four days in advance, the interviewer should call the couple one day before the appointed date to remind them of the appointment.

The interviewer should arrive at the couple's home with at least three sharpened lead pencils, a complete set of questionnaires for the couple, and a sample copy of the questionnaire instructions for his own personal use.

1. Introduce self.

2. "We appreciate your willingness to participate in this survey. We have chosen you to be a part of this survey because we wanted a mature group of students who would have a relatively high degree 
of self-awareness and sophistication and who would respond honestly and openly to the questionnaires."

3. If necessary, repeat the information given during the phone contact with emphasis on the fact that the questionnaires deal with general attitudes and opinions about family living.

4. Distribute the questionnaires one at a time reminding the couple that there are no right or wrong answers to the se questionnaires.

1) First Questionnaire - Family Friends Survey

"The first questionnaire is entitled Family Friends Survey and is to be taken by both of you together. It should take approximately 20 minutes to complete. I will read over the instructions with you."

\section{(NOTE TO INTER VIEWER)}

The interviewer should read the instructions for this questionnaire one column at a time pausing after the instructions for each column to allow the couple to complete that column,

The interviewer should spend plenty of time on the instructions to make sure the subjects have a good understanding of what is expected of them.

The interviewer should be seated in such a way so as not to be able to see the couple's answer sheet.

\section{2) Second Questionnaire - Interaction Survey}

"This second questionnaire is entitled Interaction Survey and is to be filled out individually, These questionnaires have been coded with a number and a letter (H/W) so that when all the data is collected, we can distinguish which husband and which wife make up a single couple. Your names will in no way be associated with the se codes." 
Have each spouse fill in the face sheet attached to the answer sheet. "The first page of the answer sheet is for general information and will be used to describe general characteristic s of our sample group."

"I will read over the instructions with you and answer any questions you might have." (If the parents are not living, instruct the participants to answer the questionnaire as if the parent was living.)

"Work the sample item on the instruction sheet to make sure you understand the procedure." (Check the sample for errors.)

"Please do not sit together while answering this questionnaire so that you cannot see each other's answer sheet." (Do not allow the couple to compare answers at any time.)

\section{3) Third Questionnaire - Family Problems Survey}

"This third questionnaire is entitled Family Problems Survey and is coded for the same reason as the questionnaire previously taken. I will read over the instructions with you."

\section{(NOTE TO INTERVIEWER)}

Collect each questionnaire as it is completed, glance through it to make sure it is fully and correctly completed, place it in the large manilla envelope provided. The interviewer should explain to the couple that he is "giving the questionnaire a final check to be sure that all the items on every page have been completed."

5. "Do you have any reactions to these questionnaires?"

\section{(NOTE TO INTER VIEWER)}

The interviewer's response to these reactions should be geared toward the premise that the survey deals with the general attitudes and opinions on family living and not on marriage or marital interaction.

6. "Thank you for your time and willingness to complete these questionnaires. If you are interested in the results of our study, we would be happy to send you a summary of the findings." 
October 7, 1968

Dear Student:

As part of our thesis we are conducting a survey on some aspects of marital interaction. We are looking forward to you and your spouse participating in our survey.

The survey consists of three written questionnaires. The first two are to be taken individually without prompting from your spouse. These are standardized questionnaires which have been found to be both interesting and enjoyable by large numbers of people, The third questionnaire is to be taken jointly by you and your spouse.

A member of this research team will personally contact you within the next week to discuss your participation in the survey and to arrange a convenient time for you to answer the questionnaires. The questionnaires will take a little over an hour to complete.

The information obtained from these questionnaires is strictly confidential and will in no way be personally as sociated with you and your spouse. We are interested only in the results of the questionnaires and not in the specific couples taking them. Our sample will consist of approximately fifty couples all of whom will have at least one spouse attending Portland State College School of Social Work.

Upon completion of the questionnaires, you will be given an envelope addressed to the research group. We are asking that you be responsible for returning the questionnaires. There will be no names, numbers, or other symbols used to identify you and your spouse with the completed questionnaires.

Upon completion of the thesis project, the results will be printed and a summary of the findings will be sent to you.

We appreciate your cooperation in helping us with this project.

Sincerely,

Dave Wolfington

George Henderson

Kathy Powell

Thesis Group

Portland State College

School of Social Work
Sally Wong

Linda Metz 


\section{FAMILY FRIENDS SURVEY}

The questionnaire which you have been given is to be completed with your spouse. The diagram below consists of three columns.

COLUMN I: In Column I, please write in the boxes provided the first name(s) only of as many individuals and/or couples whom you and/or your spouse consider to be your closest friend(s). By closest friend is meant any person with whom you talk about important life situations, problems, and beliefs. After each name, in the space provided, please write an $(R)$ if this individual is a relative, or an $(N)$ if this individual is not a relative. If you put the name of a single person in a box, write below that name an $(\mathrm{H})$ if this individual is contacted mainly by the husband or a $(W)$ if this individual is contacted mainly by the wife.

COLUMN II: In Column II, please circle the approximate number of contacts per month which you and/or your spouse have with each individual or couple listed. The term contact refers to any type of communication made such as letters, phone calls, visits, etc.

COLUMN III: In Column III, please indicate which of your friends are well acquainted (i.e., maintain social contacts with each other at least monthly). Draw lines connecting these friends.

\begin{tabular}{|c|c|c|c|}
\hline $\begin{array}{l}\text { COLUMN I } \\
\text { Closest Friends }\end{array}$ & $\mathrm{R} / \mathrm{N}$ & $\begin{array}{l}\text { COLUMN II } \\
\text { No. of Times Con- } \\
\text { tacted per Month }\end{array}$ & $\begin{array}{c}\text { COLUMN III } \\
\text { Friends Who Know } \\
\text { Each Other }\end{array}$ \\
\hline 1. & $\begin{array}{l}(1) \\
1 \quad 1\end{array}$ & $\begin{aligned} 1-3 & \\
& 4-6 \\
& \\
& 7 \text { or more }\end{aligned}$ & $1-\infty$ \\
\hline 2 & $\begin{array}{l}(1) \\
(\quad)\end{array}$ & $\begin{aligned} 1- & \\
4 & =6 \\
& 7 \text { or more }\end{aligned}$ & $2--$ \\
\hline 3. & $\begin{array}{l}(1) \\
(\quad)\end{array}$ & $\begin{aligned} 1- & 3 \\
& 4-6 \\
& \\
& 7 \text { or more }\end{aligned}$ & $3--$ \\
\hline 4. & $\begin{array}{l}(1) \\
(\quad)\end{array}$ & $\begin{aligned} 1-3 & \\
& 4-6 \\
& \\
& 7 \text { or more }\end{aligned}$ & $4--$ \\
\hline 5. & $\begin{array}{l}(1) \\
(\quad)\end{array}$ & 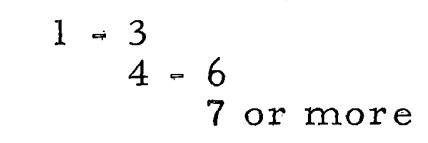 & $5--$ \\
\hline
\end{tabular}


GENERAL INFORMATION SHEET

A. Occupation:

B. Age:

C. Years of Education: High School

College

Business or other

D. Number of years married:

E. Number of children in family:

F. How long have you lived in your present community? 


\section{INTERACTION SURVEY}

Instructions:

The answer-sheet which you have been given has columns with the headings: Parent, Closest Friend, and Spouse. Please read each item on the questionnaire, and then indicate on the answer sheet the extent that you would talk about that item to each person; that is, the extent to which you would make yourself known to that person. Use the rating scale that you see on the answer sheet to describe the extent you would talk about each item. For your own convenience, in the space provided, write in which parent and which closest friend you will be referring to in responding to the items.

\section{Examples:}

Items: A, My views on communism.

B. My personal views on drinking.

Answer Sheet:

Rating Scale

0: Would tell the other person nothing about this aspect of me.

1: Would talk in general terms about this item. The other person would have only a general idea about this a spect of me.

2: Would talk in full and complete detail about this item to the other person. He would know me fully in this respect, and could describe me accurately.

X: Would lie or misrepresent myself to the other person so that he has a false picture of me.

\begin{tabular}{|c|cc|c|}
\hline$P$ & $C$ & $F$ & $S$ \\
$A$ & $L$ & $R$ & $P$ \\
$R$ & $O$ & $I$ & $O$ \\
$E$ & $S$ & $E$ & $U$ \\
$N$ & $E$ & $N$ & $S$ \\
$T$ & $S$ & $D$ & $E$ \\
& $T$ & & \\
\hline
\end{tabular}

A.

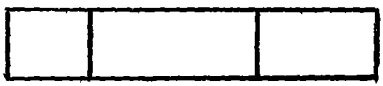

B.

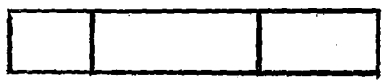


1. What I think and feel about religion; my personal religious views.

2. My views on the present government--the president, government policies, etc。

3. My views on the question of racial integration in schools, transportation, etc.

4. My personal views on sexual morality--how I feel that I and others ought to behave in sexual matters.

5. My personal standards of beauty and attractiveness in women-what I consider to be attractive in a woman.

6. The things that I regard as desirable for a man to be--what I look for in a man.

7. My feelings about how parents ought to deal with children.

8. My favorite foods, the ways I like food prepared, and my food dislikes.

9. My likes and dislikes in music.

10. My favorite reading matter.

11. The kinds of movies that I like to see best; the TV shows that are my favorites.

12. My tastes in clothing.

13. My favorite ways of spending spare time, e.g., hunting, reading, cards, sports events, parties, dancing, etc.

14. What I would appreciate most for a present.

15. What I find to be the worst pressures and strains in my work.

16. What I feel are my shortcomings and handicaps that prevent me from working as I'd like to, or that prevent me from getting further ahead in my work.

17. How I feel that my work is appreciated by others (e.g., boss, fellow-workers, teacher, husband, etc.) 
18. My ambitions and goals in my work.

19. My feelings about the salary or rewards that I get for my work.

20. How I feel about the choice of career that I have made--whether or not I'm satisfied with it.

21. How I really feel about the people that I work for, or work with.

22. How much money I make at my work, or get as an allowance.

23. Whether or not I owe money; if so, how much.

24. Whether or not I have savings, and the amount.

25. Whether or not others owe me money; the amount, and who owes it to $\mathrm{me}$.

26. All of my present sources of income--wages, fees, allowance, dividends, etc.

27. My most pressing need for money right now, e.g. , outstanding bills, some major purchase that is desired or needed.

28. How I budget my money--the proportion that goes to necessities, luxuries, etc.

29. The aspects of my personality that I dislike, worry about, that I regard as a handicap to me.

30. What feelings, if any, that I have trouble expressing or control-.. ling.

31. The facts of my present sex life--including knowledge of how I get sexual gratification; any problems that I might have; with whom I have relations, if anybody.

32. Whether or not I feel that I am attractive to the opposite sex; my problems, if any, about getting favorable attention from the opposite sex.

33. The kinds of things that just make me furious.

34. What it takes to hurt my feelings deeply. 
35. The kinds of things that make me especially proud of myself, elated, full of self-esteem, or self-respect.

36. My feelings about the appearance of my face--things I don't like, and things that I might like about my face and head--nose, eyes, hair, teeth, etc.

37. My feelings about different parts of my body--legs, hips, waist, weight, chest, or bust, etc.

38. Any problems and worries that I had with my appearance in the past.

39. Whether or not I now have any health problems--e.g., trouble with sleep, digestion, female complaints, heart condition, allergies, headaches, piles, etc.

40. Whether or not I have any long-range worries or concerns about my health, e,g, , cancer, ulcers, heart trouble.

41. Whether or not I now make special efforts to keep fit, healthy, and attractive, e.g., calisthenics, diet.

42. My feelings about my adequacy in sexual behavior--whether or not I feel able to perform adequately in sex-relationships. 


\section{ANSWER SHEET FOR INTERACTION SURVEY}

Rating Scale: 0: Would tell the other person nothing about this aspect of me.

1: Would talk in general terms about this item. The other person would have only a general idea about this aspect of me.

2: Would talk in full and complete detail about this item to the other person. He would know me fully in this respect and could describe me accurately.

$X$ : Would lie or misrepresent myself to the other person so that he has a false picture of me.
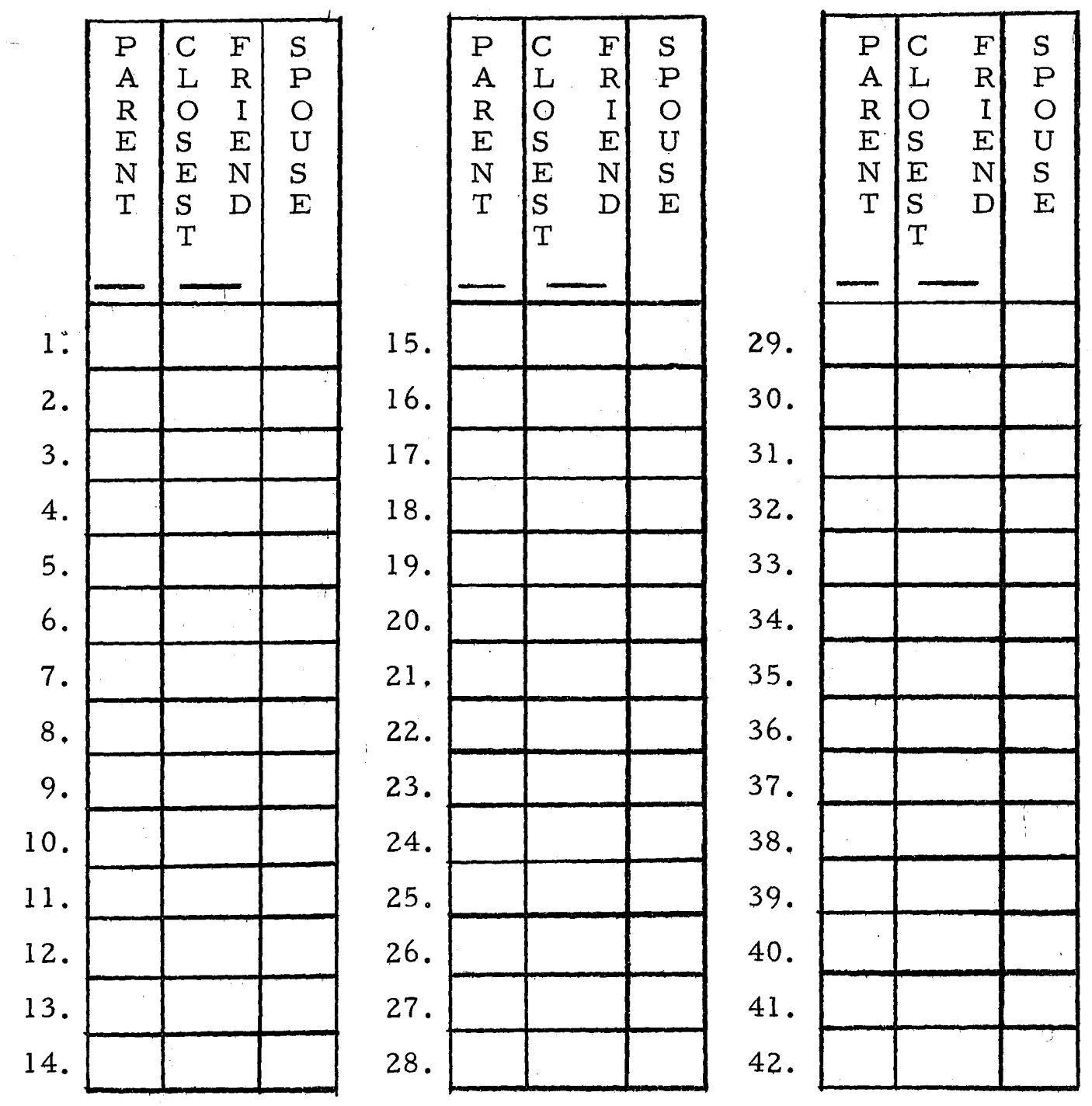
FAMILY PROBLEMS SURVEY

\section{Instructions:}

On the next page are opinions which some people have about parents and children. You will notice that there are two opinions about the same thing with the same number in front of them. Put a check mark in front of the one you agree with, Mark one opinion of each pair.

Sometimes you will find that you don't agree with either one. Then choose the one that is closer to your own idea, or the one that is a little better. If you agree with both, choose the one you like better.

Work quickly and do not linger over any one item. Check one opinion of each pair.

\section{Examples:}

X....A. Most married couples want to have at least one child.

....B. Many married couples don't ever want to have children.

....A. When a new-born baby cries, his mother can always quiet him quickly.

X....B. When a new-born baby cries, his mother sometimes does not know what to do for him.

Notice that sentence $A$ is marked in the fir st example and sentence $B$ in the second example. Now go ahead with the others. Choose one of each pair. 
1....A. You can spoil a tiny baby by picking him up every time he cries.

..... B. You cannot spoil a tiny baby by picking him up every time he cries.

2....A. Parents should not pay any attention when small children use naughty words.

....B. Parents should punish small children when they use naughty words.

3....A. It is all right for a three-year-old to have a bottle at bedtime.

...... A three-year-old is too old to have a bottle.

4,... A. A father should be his son's best pal.

..... A. A father should not try to be his son's best pal.

$5 \ldots$... If you let children eat what they want, they'll eat candy all day long.

..... B. Children usually will eat wholesome food if they are given the chance.

6....A. Teen-agers cannot be expected to be grateful to their parents.

....B. After all the sacrifices parents make, teen-age children should be grateful to them.

7.... A. If a young mother find s her baby puzzling, she should talk to some older, more experienced woman about her problems.

..... . If a young mother finds her baby puzzling, she should talk to friends her own age who have the same kinds of problems.

8.... A. Small babies should be fed when they are hungry,

$\therefore .$. . Small babies should be fed on a regular schedule.

9....A. Most people are friendly if you give them a chance.

.....B. Some people just won't warm up, no matter how friendly you are to them.

10....A. A three-year-old who wets his pants should be made to feel a shamed of himself.

...... There is no use making a child feel a shamed when he wets his pants. 
11....A. A child of 8 should have a little money to spend without telling his parents.

..... A. A child of 8 should tell his parents how he spends his money.

12....A. Breast-feeding is unpleasant for the mother.

.....B. Breast-feeding is pleasant for the mother.

13....A. A three-year-old is likely to be more disturbed by having his tonsils out than a six-year-old.

....B. It is better to have tonsils taken out at three than at six, since a three-year-old soon forgets.

$14 \ldots$... Boys and girls should use the same toilet at kindergarten.

..... B. Boys and girls should use different toilets at kindergarten.

15....A. The best way to wean a baby from the bottle is to do it gradually.

..... B. The best way to wean a baby from the bottle is to take it away and never let him see it again.

16....A. If a child is old enough to ask a question, he is old enough to be answered.

....B. Children ask questions about a lot of things they shouldn't know about.

$17 \ldots$. . It is up to the parents to train a child to have regular toilet habits.

....B. If too much fuss isn't made, a child's toilet training will take care of itself.

18....A, A lot of so-called child experts would learn a lot from having to bring up their own children.

..... . People who have studied children, even though they haven't any of their own, can contribute useful ideas to parents.

19.... A. A mother should let her baby feed himself as soon as he is able to, even if he spills a lot.

.....B. A mother should not let her baby feed himself until he can do so without too much spilling.

20.... A. Girls are usually about as destructive as boys.

...... B. Boys are usually more destructive than girls.

21.....A. If you don't get along with your own parents, you can't expect to get along with anyone else. 
.... B. Lots of people who don't get along with their own parents find much happiness with other people as they grow up.

$22 \ldots$... If a boy of 6 or 7 lies or steals, he should be punished severely.

..... L. Lying and stealing aren't very serious in boys 6 or 7 .

23....A. Nature didn't intend childbirth to be a painful experience.

.... B. Having a baby is painful, and only people who have not gone through it think that it does not have to be.

24..... A. If a two-year-old still wets his bed, he should be waked during the night and taken to the toilet.

.... B. A child should not be waked to be taken to the toilet.

25....A. No child should be permitted to strike his mother.

..... A. A mother should not be harsh with a small child who strikes her.

26..... A. Mothers should prepare good meals and let children eat what they like.

..... B. Mothers should teach children to eat everything on their plates.

27....A. Children are not concerned about things related to sex until they reach teen-age.

.... B. Even small children are interested in things related to sex.

28 .... A. No woman should be expected to have more than two children.

....B. Most women want one more baby, no matter how many children they have.

$29 . .$. A. The most difficult children to handle are the ones who are too fearful.

....B. The most difficult children to handle are the ones who are too mean and naughty.

30.... A. Parents should not ask about a five-year-old's bowel movement unless he is sick.

..... B. A child of five should be reminded every day to have his bowel movement.

31....A. The problems and worries of childhood are just as hard for children as grownup problems are for adults. 
....B. Childhood is the best time of life, and children often don't realize how lucky they are.

32....A. A six-month-old baby should be given his bottle in the crib, so his mother will have more time for work and rest.

..... A. A six-month-old baby should always be held when he is given a bottle.

33..... A. More people are doing a good job of raising children today than 30 years ago.

..... B. Fewer people are doing a good job of raising children today than 30 years ago.

34..... A. Men are much more interested than women in the physical side of marriage.

....B. Women are about as much interested as men in the physical side of marriage.

35....A. It is important to see that a young child does not form bad habits.

..... . If a young child is happy, he will not form bad habits.

36....A. There's no sense in a woman's going through the pain of childbirth when there are many drugs and modern medical techniques to prevent the pain.

..... I. It's worth taking a chance on having pain in order to be completely awake when the baby is born.

37....A. Most children have times when they hate their mothers.

....B. There is something wrong with a child who hates his mother.

38....A. If a three-year-old still sucks his thumb, his mother should prevent it or punish him.

..... A. A mother should not prevent a three-year-old from sucking his thumb, or punish him for doing so.

$39 . .$. A. If parents taught their children obedience, the children wouldn't get into trouble with the law.

..... B. When a child gets into trouble with the law, it is usually because his parents don't love him enough.

40.... A. Pregnancy is a time when most women look especially nice.

...... No matter how cleverly maternity clothes are made, a pregnant woman looks clumsy and unattractive. 
41.... A. A wife should be willing to let her husband bring a friend home to dinner on short notice.

...... A wife shouldn't be expected to have dinner ready for a guest on short notice.

$42 \ldots$. . If you are very angry towards your child, there is no use trying to hide your feelings.

....B. If you have mean feelings towards your child, you should not let the child know.

43.... A. The best way to teach children to be generous is for their parents to be generous to them.

..... B. The best way to teach children to be generous is to make them be generous to others.

44.... A. Children should be allowed to criticize their parents.

....B. Children should not be disrespectful of their parents.

45.....A. Parents of small children shouldn't go out two or three nights a week.

..... It is all right for parents of small children to go out two or three nights a week if they enjoy it.

46.... A. If an older child strikes a younger one, he should always be punished.

..... . If an older child strikes a younger one, he may have a good reason for it.

47.... A. Boys like to date "fast" girls, but when it comes to getting married, they choose girls for whom they have more respect.

....B. Most boys marry the same kind of girl they have been going out with.

48.....A. A four-year-old is more interested in sex differences than an eight-year-old.

....B. An eight-year-old is more interested in sex differences than a four-year-old.

49....A. Punishing a child doesn't do any good if you make up to him right afterwards.

....B. It is best to make up with a child right after punishing him.

50....A. It is foolish for a woman to spend time cleaning house when she has a bad cold. 
....B. A woman should keep her house neat even when she has a bad cold.

$51 \ldots$ A. It is possible to be friends with people whose actions you disapprove of.

....B. It is impossible to be friends with people whose actions you disapprove of.

52.....A. Most children nowadays aren't taught to respect their parents enough.

....B. Children have as much respect for their parents nowadays as they ever did.

53..... A. It is fun to hear a five-year-old tell big stories.

....B. A five-year-old should be taught not to tell big stories that aren't true.

54.... A. No matter how much a woman wants a baby, pregnancy is an unpleasant experience.

....B. Most women find pregnancy an especially pleasant time of life.

$55 . .$. A. It is wonderful to have your own mother with you when you come home from the hospital with a new baby.

..... A. A woman is better off with outside help instead of her own mother when she comes home from the hospital with a new baby.

56.... A. Most mothers nowadays let their children get away with too much.

..... M. Most mothers nowadays do a pretty good job of raising their children. 
SCORE SHEET FOR INTERACTION SURVEY

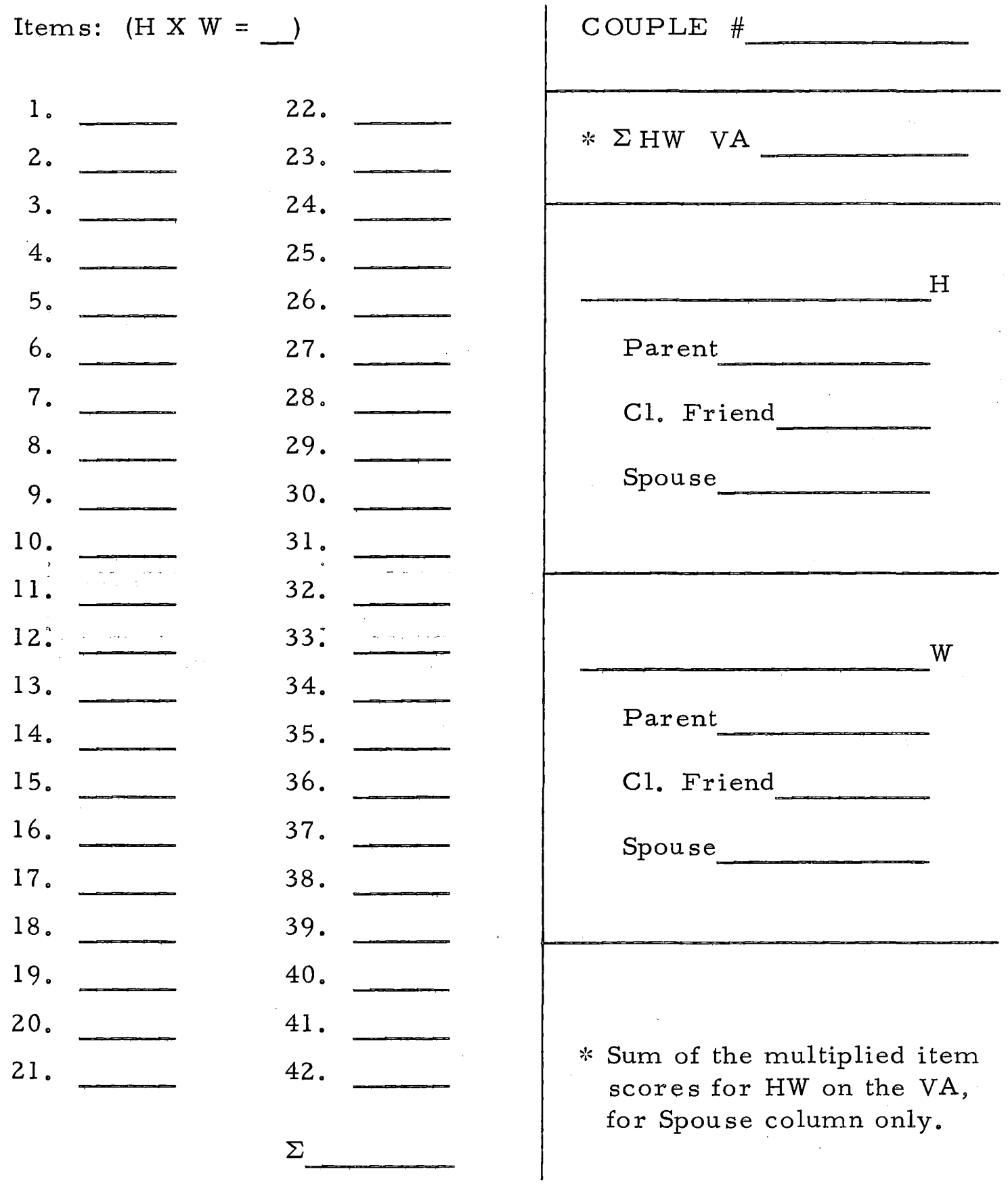


SCORE SHEET FOR FAMILY PROBLEMS SURVEY

AFI

CLUSTER I

$1 \mathrm{a}$

2a. b.

$3 a$.

$4 a$.

6a. $\quad b$

$7 a$.

8a.

9 a.

$10 \mathrm{a}$

$11 \mathrm{a}$.

$13 a$.

$14 \mathrm{a}$.

$16 a$.

$17 \mathrm{a}$.

$18 \mathrm{a}$.

$19 a$

$21 \mathrm{a}$.

$22 \mathrm{a}$.

$24 a$.

$25 a$.

$26 a$.

$27 a$.

30 a.

31 a.
$32 a$.

$33 a$.

$35 a$.

$37 a$. b.

$38 a$.

b.

$39 a$.

b.

$41 \mathrm{a}$.

b.

$42 a$.

b.

$43 a$.

$44 a$.

$45 a$.

$46 a$.

$47 \mathrm{a}$.

$48 \mathrm{a}$

$49 a$.

$50 \mathrm{a}$.

$50 a$

$51 \mathrm{a}$

$52 a$.

$53 a$.

$55 a$.

b.

b.

b.

b.

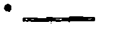

-
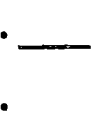

b.

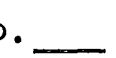

-

-

.

b.

b.

b.

b.

b.

b.

b.

b.

b.

$56 a$. b.

b.
RW BR

CLUSTER IV

$5 a$.

b.

$12 \mathrm{a} . \ldots \mathrm{b}$.

15a. b.

20a. b.

23a.b.

$28 a$. _ b b

29a. b.

$34 a$.

b.

$36 a$. b.

40a. b.

$54 a$. b.

Total 
TABLE IX

VERBAL ACCESSIBILITY (VA) FOR THREE TARGET PERSONS

\begin{tabular}{lccccc}
\hline $\begin{array}{c}\text { Target } \\
\text { Person }\end{array}$ & $\begin{array}{c}\text { Number } \\
\text { of } \\
\text { Cases }\end{array}$ & Range & Mean & Variance & $\begin{array}{r}\text { Standard } \\
\text { Deviation }\end{array}$ \\
\hline Spouse & 100 & $54-84$ & 76.55 & 63.69 & 7.98 \\
Parent & 100 & $12-84$ & 50.89 & 326.38 & 18.07 \\
Friend & 100 & $23-84$ & 56.55 & 261.93 & 16.18 \\
\hline
\end{tabular}

